Illinois State University

ISU ReD: Research and eData

Theses and Dissertations

3-26-2018

\title{
Understanding 1-D Vertical Flux Dynamics In A Low-Gradient Stream: An Assessment Of Stage As A Control Of Vertical Hyporheic Exchange
}

Frances Claire Harris

Illinois State University, harrisfc16@gmail.com

Follow this and additional works at: https://ir.library.illinoisstate.edu/etd

Part of the Geographic Information Sciences Commons, and the Hydrology Commons

\section{Recommended Citation}

Harris, Frances Claire, "Understanding 1-D Vertical Flux Dynamics In A Low-Gradient Stream: An Assessment Of Stage As A Control Of Vertical Hyporheic Exchange" (2018). Theses and Dissertations. 861.

https://ir.library.illinoisstate.edu/etd/861

This Thesis is brought to you for free and open access by ISU ReD: Research and eData. It has been accepted for inclusion in Theses and Dissertations by an authorized administrator of ISU ReD: Research and eData. For more information, please contact ISUReD@ilstu.edu. 


\section{UNDERSTANDING 1-D VERTICAL FLUX DYNAMICS IN A LOW-GRADIENT STREAM: AN ASSESSMENT OF STAGE AS A CONTROL OF VERTICAL HYPORHEIC EXCHANGE}

\section{FRANCES CLAIRE HARRIS}

\section{Pages}

Little Kickapoo Creek (LKC) is a low-gradient, third-order perennial stream with headwaters in Bloomington, IL. The objective of this study is to characterize vertical onedimensional (1-D) flux rates in the top $150 \mathrm{~cm}$ of the streambed, test the viability of a heat tracing method in a low-gradient area, and determine the relationship between stage and 1-D vertical flux rates. In 2009, six wells were installed along the thalweg of the stream in a 25-meter stretch spaced at 5-meter intervals. Each well recorded temperature at five separate depths logging at 15-minute intervals from February 2009 to March 2010: 30, 60, 90, and $150 \mathrm{~cm}$. Stage data was collected at 15 -minute intervals on the stream bank adjacent to the streambed well array. Vertical flux rates are calculated using temperature sensor pairs at depth with the 1-D conduction-advection-dispersion equation utilized in the VFLUX MATLAB program.

Flux calculations are at the midpoint between a sensor pair, e.g., a flux is estimated at a depth of $45 \mathrm{~cm}$, the midpoint between the 30 and $60 \mathrm{~cm}$ sensors. The dominant flux direction at a depth of $15 \mathrm{~cm}$ is downward (negative) while the average flux direction at a depth of $45 \mathrm{~cm}, 75$ $\mathrm{cm}$, and $120 \mathrm{~cm}$ is upward (positive). Fluxes at a $15 \mathrm{~cm}$ depth for all six wells ranges between 0.59 to $0.95 \mathrm{~m} / \mathrm{d}$ with an average of $-0.04 \mathrm{~m} / \mathrm{d}$. At a midpoint of $45 \mathrm{~cm}, 75 \mathrm{~cm}$, and $120 \mathrm{~cm}$ fluxes are highly variable with high-frequency spikes and missing data, but all have a baseline 
upward trend. Due to the errors in flux, the paper focuses on a depth of $15 \mathrm{~cm}$ within the hyporheic zone of LKC for the stage correlation analysis. At a $15 \mathrm{~cm}$ depth, the average flux across six wells ranges from $-2 * 10^{-6} \mathrm{~m} / \mathrm{s}$ to $5^{*} 10^{-7} \mathrm{~m} / \mathrm{s}$. The hyporheic zone at LKC has variable flux directions above $15 \mathrm{~cm}$ indicating hyporheic exchange with background upwelling groundwater between 15 to $120 \mathrm{~cm}$. Flux rates approach zero in the summer meaning a period of limited hyporheic exchange.

The relationship between stage and flux at the near-surface streambed $(15 \mathrm{~cm})$ is a weak, but statistically significant with Spearman's rank correlations for all six wells at $15 \mathrm{~cm}$ depth ranging from -0.032 to 0.369 with an average of 0.085 . A negative relationship implies that as stage rises and the stream loses water (negative, downward flux) from the streambed and vice versa. A positive relationship explains that as stage rises the stream is in a gaining condition (upward, positive flux). With the assumption that flux does not have an instantaneous reaction to a change in stage, a cross-correlation analysis was performed. The cross-correlation analysis keeps stage stagnant in time, while flux is temporally shifted forward. The highest Spearman's coefficient is 0.442 for well 4 . The other five wells have a Spearman's coefficient less than 0.20. This research indicates that stage is not a reliable prediction of 1-D vertical flux in the hyporheic zone of LKC. Vertical flux is a multivariate function that can be controlled by the following variables: stream velocity, streambed morphology and topography, streambed conductivity, channel slope, stream sinuosity, vertical gradient in the microscopic stream-streambed and watershed scale, and stream stage or discharge.

KEYWORDS: Little Kickapoo Creek; Low-Gradient Stream; Hyporheic Zone; 1-D Vertical Hyporheic Flux; Hyporheic Exchange; Heat as a Tracer 


\title{
UNDERSTANDING 1-D VERTICAL FLUX DYNAMICS IN A LOW-GRADIENT STREAM: AN ASSESSMENT OF STAGE AS A CONTROL OF VERTICAL HYPORHEIC EXCHANGE
}

FRANCES CLAIRE HARRIS

\author{
A Thesis Submitted in Partial \\ Fulfillment of the Requirements \\ for the Degree of \\ MASTER OF SCIENCE \\ Department of Geography, Geology, and the Environment \\ ILLINOIS STATE UNIVERSITY
}


(C) 2018 Frances Claire Harris 


\section{UNDERSTANDING 1-D VERTICAL FLUX DYNAMICS IN A LOW-GRADIENT STREAM: AN ASSESSMENT OF STAGE AS A CONTROL OF VERTICAL HYPORHEIC EXCHANGE}

FRANCES CLAIRE HARRIS

COMMITTEE MEMBERS:

Eric W. Peterson, Chair

Jonathan Thayn

Wondwosen Seyoum 


\section{ACKNOWLEDGMENTS}

First, I would like to thank Dr. Eric Peterson, whose guidance, both scientific and professional, has made me a better scientist. I am grateful for your patience and mentorship through multiple projects. I am indebted for the skills I have acquired throughout your advisement. Second, I would like to thank Dr. Jonathan Thayn for your support with my data processing, coding, and statistics. Last, but not least, I would like to express my gratitude to Dr. Wondwosen Seyoum for your help analyzing my results and ability to provoke critical thinking. I am incredibly appreciative and privileged to have worked with a group of such driven and intelligent advisors.

I am also thankful for the Department of Geography, Geology, and the Environment at Illinois State University who provided the necessary resources for the completion of my thesis. I feel fortunate to have worked with such an accepting group of graduate students; Thank you for your advice, constructive criticism, and friendship. I greatly appreciate my parents for their moral support throughout my studies. Your hard work, guidance, love, and support made my thesis possible. Finally, I would like to thank my boyfriend Vincent for his unconditional love and support.

F. C. H. 


\section{CONTENTS}

Page

ACKNOWLEDGMENTS

$\begin{array}{ll}\text { CONTENTS } & \text { ii }\end{array}$

TABLES $\quad$ iv

FIGURES

CHAPTER I: INTRODUCTION AND RESEARCH OBJECTIVES 1

$\begin{array}{ll}\text { Introduction } & 1\end{array}$

$\begin{array}{ll}\text { Research Objectives } & 4\end{array}$

$\begin{array}{ll}\text { CHAPTER II: BACKGROUND } & 6\end{array}$

Study Site: Little Kickapoo Creek $\quad 6$

$\begin{array}{ll}\text { CHAPTER III: METHODOLOGY } & 10\end{array}$

$\begin{array}{ll}\text { Data Collection } & 10\end{array}$

$\begin{array}{ll}\text { Flux Calculations } & 11\end{array}$

Statistics: Stage and Vertical 1-D Flux 16

$\begin{array}{ll}\text { CHAPTER IV: RESULTS } & 18\end{array}$

Trends in Raw Temperature Data and Vertical 1-D Flux 18

Correlation of Stage and 1-D Flux 29

CHAPTER V: DISCUSSION

Low-Gradient Stream Conceptual Model - Temperature and Flux dynamics 32

Stage as a Control of 1-D Vertical Flux 35

CHAPTER VI: CONCLUSION

$\begin{array}{ll}\text { REFERENCES } & 41\end{array}$ 
APPENDIX: TEMPERATURE AND FLUX AT WELLS 2-6 


\section{TABLES}

Table

Page

1. Parameters Used in Flux Calculations

2. Seasonal Amplitude Averages for 30, 60, 90, $150 \mathrm{~cm}$ Depths

3. Average Seasonal Peclet Numbers (Pe) at each Midpoint Depth

4. Spearman's Rank Correlation Coefficients for all Six Wells at $15 \mathrm{~cm}$ Midpoint Depth 


\section{FIGURES}

Figure

1. Map of Little Kickapoo Creek Watershed and Site Configuration in Plan View 8

2. Stratigraphic Column of Formations at Little Kickapoo Creek Study Site 9

3. Longitudinal Cross-section of Streambed Well Array 11

4. Phase Shift and Amplitude Dampening of Thermal Signals with Increasing Depth 14

5. Well 1 Temperature in Stream, 30, 60, 90, and $150 \mathrm{~cm}$ Depth with Stage

$\begin{array}{ll}\text { Time Series } & 18\end{array}$

6. Week-long Temperature Time Series at 30, 60, 90, $150 \mathrm{~cm}$ Depth 21

7. Week-long Temperature Time Series with Storm Events at 30, 60, 90, $150 \mathrm{~cm}$ Depth

8. Complete 13-month Raw Temperature Time Series and the Diurnal (24-hour) Component Isolated from the Raw Temperature Time Signal by the DHR Model

9. Well 1 Calculated 1-D Vertical One-Dimensional Flux and Amplitude Ratio

10. Calculated Flux at $15 \mathrm{~cm}$ Depth for all Six Wells, Raw Precipitation, and Stage Data 26

11. Sensitivity Analysis for Independent Variables Used in Flux Calculations 


\section{CHAPTER I: INTRODUCTION AND RESEARCH OBJECTIVES \\ Introduction}

The relationship between fluid flow and heat transfer is a powerful tool in groundwater hydrology. The application of heat flow theory in the realm of groundwater hydrology was initiated in the early 1900s and revisited in the 1960s, using analytical solutions to partial differential equations (Stallman, 1965; Suzuki, 1960). Following the foundational work produced in the 1960s, heat tracing methods resurfaced in the 1980s. During this period, temperature tracing methods became an increasingly popular method to study surface water-groundwater interactions (SW-GW) because temperature is easily-measurable and inexpensive compared to other tracing techniques. Temperature profiles are used to quantify one-dimensional (1-D) rates and vertical hydraulic conductivity in the hyporheic zone (Lapham, 1989), indicate areas of recharge and discharge along the streambed (Conant 2004; Silliman and Booth 1993), and delineate the active surface-water mixing zone in the streambed (Conant 2004). Hyporheic water exchange is often dynamic, and thermal signatures apply to studies with transient fluxes at varying temporal scales (Jensen and Engesgaard, 2011; Allander, 2003). Heat tracing methods that use periodic temperature signals are becoming increasingly user-friendly (Hatch et al., 2006; Keery et al., 2007; Luce et al., 2013; McCallum et al., 2012).

Thermal profiles quantify vertical fluxes using the heat flow equation (Hatch et al., 2006; Keery et al., 2007). The use of heat as a tracer is an effective method to measure SW-GW exchange because it is non-reactive, low-budget, and naturally occurring. Heat conduction and convection govern thermal conditions in the streambed (Stallman, 1965). Convection is the transfer of heat driven by fluid movement related to two mechanisms: diffusion (microscopic) and advection (macroscopic). Advection is a directly related to Darcy's flux driven by a 
hydraulic gradient. Heat transfer by conduction occurs on a molecular level described by Fourier's Law. Thermal transfer by conduction occurs through molecular collisions that are driven by a temperature gradient. Fourier's Law is the thermodynamic equivalent of Darcy's Law. The context and connection between heat flow theory and Darcy's Law is necessary because temperature can be used as a proxy for fluid movement. The heat flow equation and its direct application to the 1-D conduction-advection-dispersion heat equation is compared to Darcy's Law by Theis (1935) and Freeze (1985). Anderson (2005) states:

"The quantitative theory of heat flow is a proxy for Darcy's Law, with connections between the following parameters: hydraulic pressure to temperature, pressure gradient to thermal gradient, permeability to thermal conductivity, and specific yield to specific heat."

The 1-D conduction-advection-dispersion heat equation governs thermal conditions in the streambed by incorporating molecular and mass flow heat transfer (Goto et al., 2005; Stallman, 1965). Stallman (1965) created an analytical expression of the 1-D heat equation to solve for percolation rates from surface water bodies that incorporate the periodic nature of temperature. Since then, several analytical models utilizing a derivation of Stallman's heat equation expression have been produced (Goto et al., Hatch et al., 2006; Keery et al., 2007; Lapham, 1989; Luce et al., 2013; McCallum et al., 2012). Hatch et al. (2006) used the phase angle, or amplitude, of each corresponding day of a temperature signal to calculate a mean flux rate between a pair of temperature sensors. This model applied a band-pass filter to extract the temperature signal (Hatch et al., 2006). Keery et al. (2007) extracted temperature signals using a Dynamic Harmonic Regression (DHR) and Young et al. (1999) calculated flux with an amplitude and phase angle approach. Both Keery et al. (2007) and Hatch et al. (2006) used the 
derivations of the heat equation, including amplitude ratio or phase lag between two temperature signals, at varying depths. Recently, analytical models that incorporate an amplitude-phase angle combination approach to calculating vertical pore water flux have been developed (Luce et al., 2013; Mccallum et al., 2012). Calculating pore water flux in the hyporheic zone involves minimal effort with the advancement of several automated programs: Ex-Stream (Swanson and Cardenas, 2011) or VFLUX (Gordon et al., 2012; Irvine et al., 2015). The 1-D vertical flux analytical solutions of the Keery et al. (2007), Hatch et al. (2006), Luce et al. (2013), and McCallum et al. (2012) can all be used in VFLUX (Gordon et al., 2012; Irvine et al., 2015).

Darcy's Law describes fluid movement driven by gravity and a pressure gradient. Stage or the stream scale hydraulic gradient should force stream water into the streambed via hydrostatic compression. Few studies have looked at the hydrostatic control of the stream on hyporheic exchange. An understanding of the influence of vertical gradients, lateral gradients, and discharge are developing in high gradient settings (Ward et al., 2012; Ward et al., 2017; Ward et al., 2016; Schmadel et al., 2017). Most studies analyzing hydrostatic controls of hyporheic exchange focused on microscopic streambed features. Analyses to understand the geomorphic conditions controlling hyporheic exchange are more frequent and understood (Harvey and Bencala, 1993; Kasahara and Wondzell, 2003; Storey et al., 2003; Wondzell and Gooseff, 2013). Fluctuating fluvial streambed morphology, or "stream slope variability," can drive hyporheic exchange through elevation differences (Harvey and Bencala, 1993). The differential pressure across bedforms forces fluid through the streambed (Harvey and Bencala, 1993; Kasahara and Wondzell, 2003). Cardenas et al. (2004) found significant hyporheic exchange across streambed forms and discovered a positive correlation between bedform amplitude and spacing to total hyporheic exchange. The controls on SW-GW interaction are 
relevant to a variety of ecological, water quality, and watershed allocation models because hyporheic exchange and storage is a part of a watershed systems mass balance, a habitat for stream ecology, and a host to various critical biogeochemical reactions.

Groundwater and surface water were initially considered discontinuous sources, but research indicates that these two reservoirs are interconnected and are better regarded as one entity (Woessner, 2000; Boulton et al., 1998; Winter, 1998). It is essential to understand and to quantify surface water and groundwater interaction to gain a fundamental understanding of a basin's stream ecology (Stanfard, 1998). There is a lack of knowledge on the hydrodynamic controls in the hyporheic zone or the ecotone. Since surface water and groundwater are in constant interaction, stream ecosystems are thought to spatially include the hyporheic zone (Mulholland and DeAngelis, 2000). Stream water can exchange entirely with groundwater in the hyporheic zone along a few kilometers (Harvey and Wagner, 2000). The qualitative definition of the hyporheic zone is a spatially and temporally variable ecotone between stream water and groundwater where many ecological processes occur (Boulton et al., 1998; Vervier et al., 1992). To protect water resources and the ecological health of a stream, a thorough understanding of pore water dynamics in the hyporheic zone is critical (Woessner, 2000; Stanford, 1998).

\section{Research Objectives}

The Hatch et al. (2006) method is applied, using the MATLAB toolbox VFLUX (Gordon et al., 2012; Irvine et al., 2015), to generate a one-dimensional (1-D) vertical pore water flux between the temperature sensors in each of the 6 piezometer nests in Little Kickapoo Creek (Hatch et al., 2006; Gordon et al., 2012; Irvine et al., 2015). Estimates of 1-D vertical fluxes across the longitudinal streambed well array at four separate depths allows for temporal analysis 
of gaining and losing conditions in a low-gradient, gaining stream. The objective of the research is to answer the following questions:

(1) Does stage control direction and magnitude of vertical flux? Is there a linear correlation between these two parameters?

(2) How does flux change temporally?

Hydraulic head is directly proportional to the potential energy per unit mass of fluid (Deming, 2002). Water naturally flows from areas of high to low hydraulic head or regions of high to low potential energy (Deming, 2002). Based on this idea, I am proposing that there will be a linear relationship between stage and flux. A negative direct correlation would mean a rise in stage would induce losing conditions in the stream (increased negative flux) and if the stage decreases the stream will be gaining (increased positive flux). Little Kickapoo Creek is characterized as a perennially gaining stream (Peterson and Sickbert, 2006). I am proposing that flux will be inversely proportional to stage. As stage increases, the magnitude of flux will increase and become more negative. When stage, the flux direction and magnitude will increase in the positive or upward direction. LKC has been defined as a perennially gaining stream by various chemical solute and thermal models; therefore, fluxes should stay positive annually (Bastola and Peterson, 2016; Buyck, 2005; Hayden, 2012; Oware, 2010). 


\section{CHAPTER II: BACKGROUND}

\section{Study Site: Little Kickapoo Creek}

Little Kickapoo Creek (LKC) is a low-gradient, third-order perennial stream with headwaters in Bloomington, IL. Located south of Bloomington, Illinois (Fig. 1), the study site is positioned along Little Kickapoo Creek with a drainage area of $57.5 \mathrm{~km}^{2}$. The stream site segment is unmodified, with a sinuosity index of 1.8 meandering through an alluvial valley (Peterson and Sickbert, 2006). LKC is in central Illinois, a humid region with warm summers and cold winters. The warmest months are June, July, and August with mean monthly temperatures above $20^{\circ} \mathrm{C}$. The coldest months are December, January, and February with mean monthly temperatures below $0^{\circ} \mathrm{C}$. The average monthly precipitation from 1981 through 2010 was $83 \mathrm{~mm}$. Monthly precipitation in 2009 was higher than the $2009-2010$ monthly average normal values.

During the Wisconsin glacial episode between 14,100 to 23,000 years ago, an end moraine system developed up-gradient of the study site (Hartz, 2016). LKC flows across a valley-train outwash deposit that was formed by glacial meltwater (Riggs, 1997). There are three formations included at the LKC study site ordered from youngest to oldest (Fig. 2): the Cahokia Alluvium, the Henry Formation, and the Tiskilwa Formation.

The Tiskilwa Formation is one of four units comprising the Wedron Group deposited during the Wisconsin episode (Hansel and Johnson, 1996). The Tiskilwa Formation is a redbrown to red-gray diamicton interpreted as glacial till (Fig. 2; Hansel and Johnson, 1996). It is composed of 25-40\% clay, the balance being sand and gravel (Fig. 2; Hansel and Johnson, 1996). The Tiskilwa Formation has a hydraulic conductivity of $1.0 \times 10-8 \mathrm{~m} / \mathrm{s}$, which is two orders of magnitude less than the hydraulic conductivity of the Henry Formation (Ackerman, 
2015). The sharp contrast between the hydraulic conductivity values of the Tiskilwa and the Henry Formations, forces flow through the overlying Henry Formation (Fig. 2; Peterson and Benning, 2013; Ackerman, 2015). Therefore, the Tiskilwa Formation can be considered a confining layer (Peterson and Benning, 2013; Ackerman, 2015).

The light gray Henry Formation, dominated by coarse sand and gravel (Fig. 2; Willman and Frye, 1970), was deposited during the glacial outwash event during the Wisconsin episode as the ice sheet was up-gradient (Hansel and Johnson, 1996). The formation ranges from 5-7 meters in thickness across the LKC valley but is approximately 6 meters thick at the study site (Peterson and Sickbert, 2006). The Henry Formation has a vertical hydraulic conductivity of 1.0 x 10-6 m/s (Ackerman, 2015). The Henry Formation serves as the material of the streambed controlling the material parameters used in this study. It is the main unconfined aquifer in the area and underlies the Cahokia Alluvium (Fig. 2; Peterson and Sickbert, 2006).

The Cahokia Alluvium is approximately 2 meters thick at the study reach (Fig. 2; Basu, 2007). The Cahokia Alluvium is composed of a light yellow to brown silt with sand and gravel (Fig. 2; Hansel and Johnson, 1996). The Cahokia Alluvium is finer grained than the Henry Formation (Fig. 2; Hansel and Johnson, 1996). The sand and silt deposits of the Holocene age Cahokia Alluvium were deposited by modern streams (Riggs, 1997). The Cahokia Alluvium laterally extends across the entire 200-meter outwash channel (Basu, 2007). The sharply incised banks of LKC cuts through the Cahokia Alluvium unit. The vertical distance from the substrate to the bank tops is approximately 2 meters. The Cahokia Alluvium stratigraphically overlies the Henry Formation and is not considered a confining unit (Fig. 2; Peterson and Benning, 2013).

The stream has a strong connection to the Henry Formation. Peterson and Sickbert (2006) found that the hydraulic head of the water table near the creek mimics the stage of LKC with a 
minimal lag time between the peak stage during a flood event and the measured hydraulic head in the aquifer (Peterson and Sickbert, 2006). At the regional scale, LKC is considered a gaining stream that has a baseflow of $0.1 \mathrm{~m}^{3} / \mathrm{s}$ (Peterson and Sickbert, 2006) with external inputs from agricultural tile drains (Kisfalusi, 2016). Tile input does not alter the thermal conditions in the stream because the tile discharge is not significant enough to overcome the streams thermal inertia. The hyporheic zone has a mean hydraulic conductivity of 2x10-3 m/s (Bastola and Peterson, 2016). Within the outwash valley, groundwater flow converges towards the stream (Peterson and Sickbert, 2006).

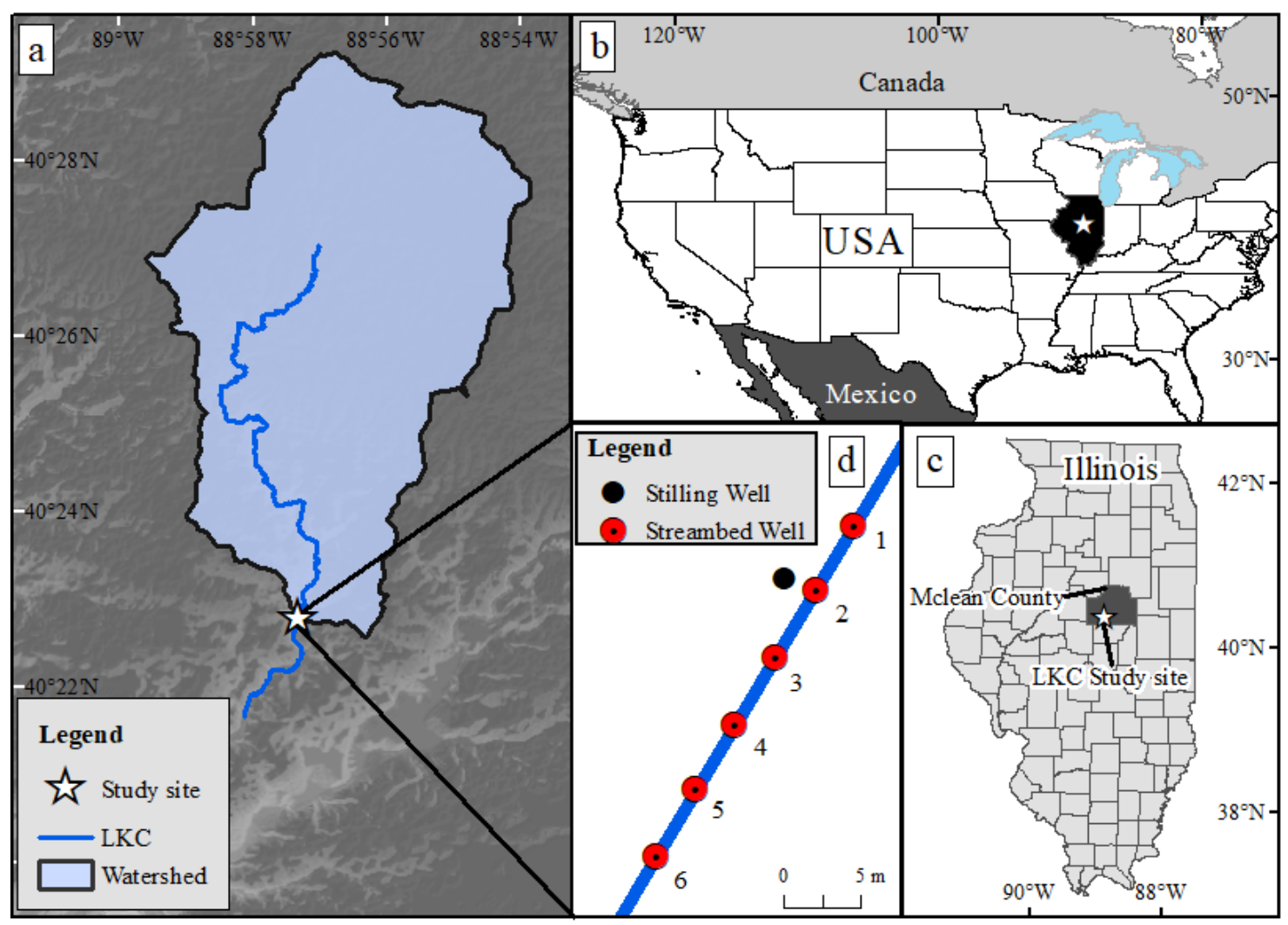

Fig. 1 a) Map of Little Kickapoo Creek $(L K C)$ watershed and the site configuration in plan view (d). The study site is in Mclean County, Bloomington, Illinois (b; c). d) There are six streambed wells installed along the thalweg of the stream. The stilling well was installed on the stream bank in line with the second well that monitored stage at a 15-minute interval. 


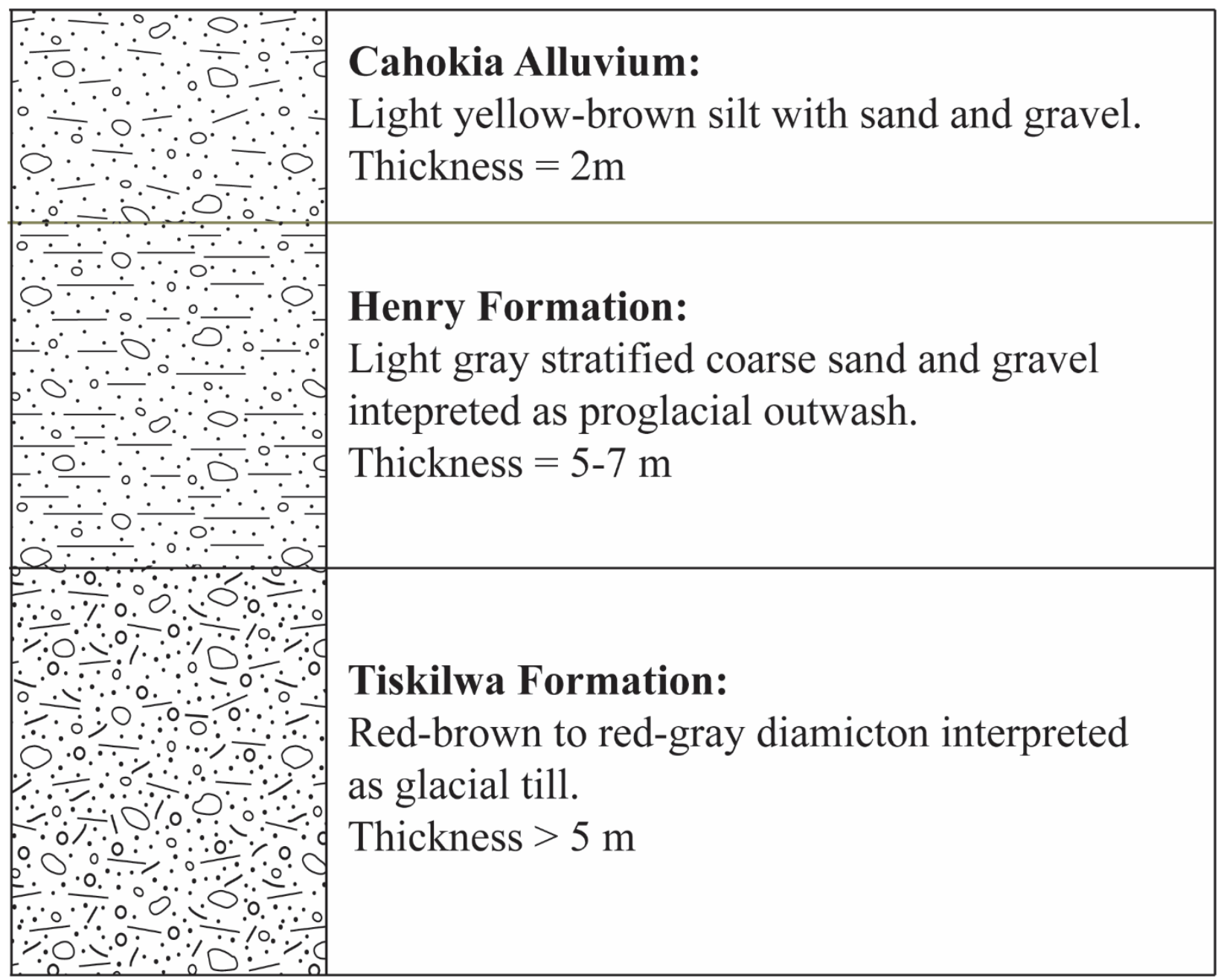

Fig. 2 Stratigraphic column of formations at Little Kickapoo Creek study site (Figure modified from Hartz (2016). The Henry formation comprises the streambed and acts as the primary unconfined aquifer of the area. 


\section{CHAPTER III: METHODOLOGY}

\section{Data Collection}

Six piezometer nests were installed along the thalweg of a 25 -meter stretch of LKC by Erasmus Oware and Hyridya Bastola (Fig. 1 and 7; Oware, 2010; Bastola and Peterson, 2016). This segment was chosen because of its low sinuosity, reducing the effects of induced flow through point bars (Peterson and Sickbert 2006; Bastola and Peterson, 2016; Van der Hoven et al. 2008). The wells were separated at 5-meter intervals with the first well located upstream and the sixth well downstream (Fig. 1 and 3; Oware, 2010). A stilling well monitoring stage at a 15minute interval was located directly adjacent to well (Oware, 2010). The six in-stream wells were made of a $3.51 \mathrm{~cm}$ PVC pipe with four sealed chambers in each tube to prevent vertical mixing (Fig. 3; Bastola and Peterson, 2016). Holes were drilled into each chamber to allow for thermal mixing and equilibrium of the corresponding streambed depths (Bastola and Peterson, 2016). The piezometer nests included a temperate sensor at four separate depths logging at 15minute intervals: 30, 60, 90, $150 \mathrm{~cm}$ (Fig. 3; Bastola and Peterson, 2016). Well one and six had temperature loggers that recorded stream temperature (Bastola and Peterson, 2016). The streambed and stream temperature was measured with $\mathrm{HOBO}{ }^{\circledR}$ Pendant Data Loggers (at $25^{\circ} \mathrm{C}$ accuracy: \pm 0.53 ; resolution: $0.14^{\circ} \mathrm{C}$ ). The temperature dataset includes a year of data from February 2009 to March 2010 (Bastola and Peterson, 2016). 


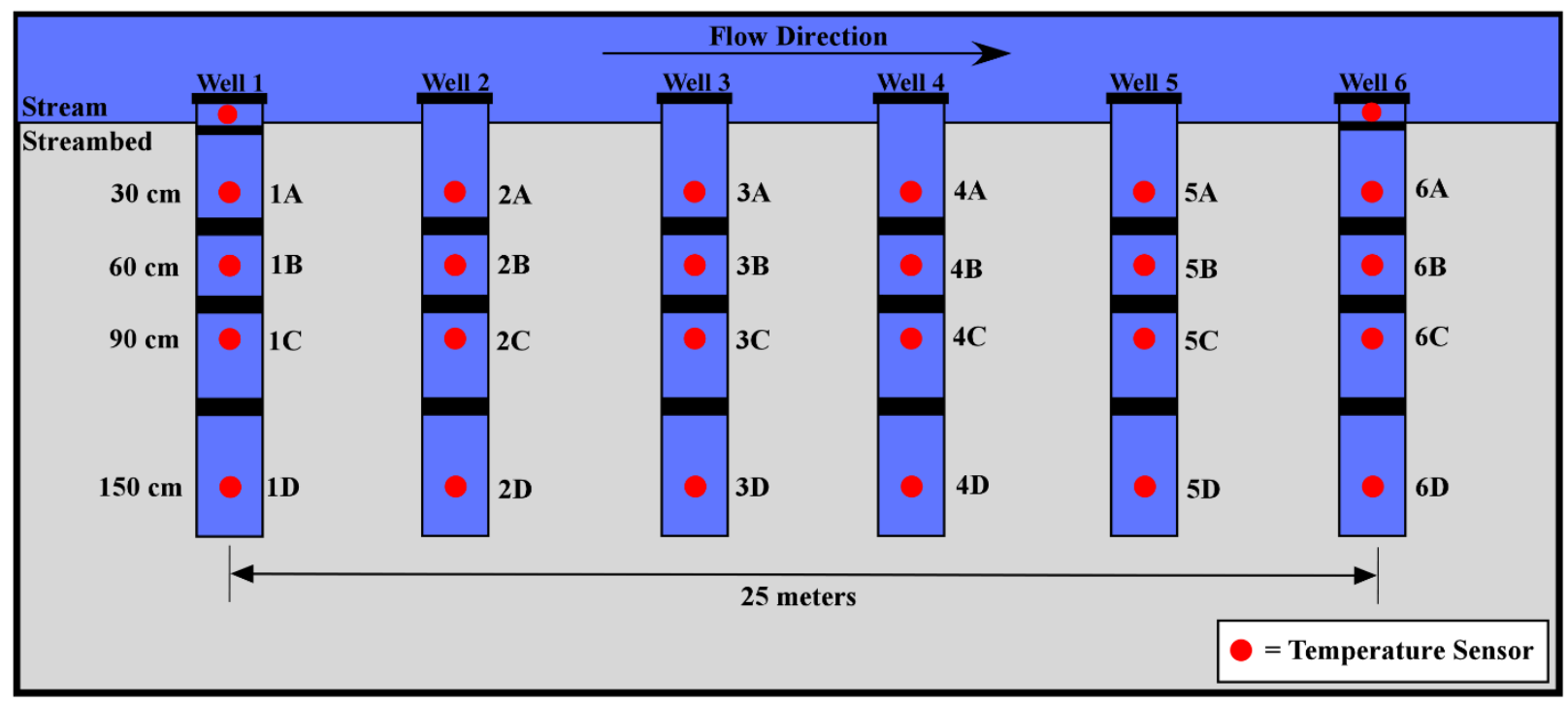

Fig. 3 Longitudinal cross-section of streambed well array. There are four streambed temperature sensors in all 6 wells at 30,60,90,150 cm depth. There are two stream temperature sensors in well 1 and 6. The wells were installed along the thalweg of Little Kickapoo Creek (graphic modified from Bastola and Peterson, 2016).

\section{Flux Calculations}

Flux is calculated at the midpoint of each temperature sensor at depth, rendering four flux values per well. With the assumption that all energy is conserved, the rate of thermal energy changing in a system will be the sum of individual rates of three separate mechanisms: conduction, convection (commonly referred to as 'advection'), and internal heat generation (Deming, 2002). Internal heat generation will not be considered at Little Kickapoo creek because no internal heat sources are affecting the hyporheic zone in this area. Therefore, the two mechanisms influencing heat flow in Little Kickapoo Creek are conduction and convection. For the purposes of this paper, convection is mass movement within the stream and advection is the mass movement in the streambed. Convection and advection transport heat by physical movement, such as mass fluid flow, and conduction transports heat by molecular collisions 
(Deming, 2002). Groundwater transports heat through advection and conduction; therefore, the heat governing equation can be manipulated to render hyporheic flux (Stallman, 1965; Anderson. 2005).

Vertical fluxes are calculated using a one-dimensional conduction-advection-dispersion equation:

$\frac{\partial \mathrm{T}}{\partial \mathrm{t}}=K_{e} \frac{\partial^{2} \mathrm{~T}}{\partial \mathrm{z}^{2}}-\frac{\mathrm{n} v_{f}}{\gamma} \frac{\partial \mathrm{T}}{\partial \mathrm{t}}$

Where temperature, T, varies with time, t, and depth, z (Stallman, 1965; Anderson, 2005; Hatch et al., 2006). All input parameters for flux calculations are in Table 1 . The second term in the equation is the conduction-dispersion term. Conduction is dependent on the effective thermal diffusivity $\left(\mathrm{K}_{\mathrm{e}}\right)$ and the change in thermal gradient (Deming, 2002). Thermal diffusivity is dependent on thermal dispersivity $(\beta)$, baseline thermal conductivity in the absence of fluid flow $\left(\lambda_{o}\right)$, the linear fluid velocity, and the volumetric heat capacity of the streambed $\left(\mathrm{C}_{\mathrm{s}}\right)$ (Hatch et al., 2006; Gordon et al., 2012; Irvine et al., 2015; Table 1).

$K_{e}=\frac{\lambda_{o}}{C_{s}}+\beta\left|v_{f}\right|$

The third term in the equation 1 represents convection including porosity $(n)$, fluid velocity $\left(v_{f}\right)$, and the ratio of the volumetric heat capacity of the streambed $\left(\mathrm{C}_{\mathrm{s}}\right)$ to the volumetric fluid heat capacity $\left(\mathrm{C}_{\mathrm{w}}\right)$ denoted as $\gamma$ (Anderson, 2005; Hatch et al., 2006). The porosity and fluid velocity represent the fluid flux (q), which Hatch et al. (2006) and Keery et al. (2007) solved for flux using the attenuation of the amplitude (amplitude ratio) of sinusoidal temperature signals propagating vertically into the streambed. 
Table 1 Parameters used in flux calculations.

\begin{tabular}{|c|c|c|c|}
\hline Parameter & Symbol & Value & Source \\
\hline Porosity & $\mathrm{n}$ & 0.375 & Bastola and Peterson (2016) \\
\hline Dispersivity $(\mathrm{m})$ & $\beta$ & 0.005 & Bastola and Peterson (2016) \\
\hline Thermal Conductivity $(\mathrm{cal} / \mathrm{sec}-\mathrm{cm}-\mathrm{C})$ & $\lambda_{\mathrm{o}}$ & 0.0033 & Bastola and Peterson (2016) \\
\hline Volumetric heat capacity of sediment $\left(\mathrm{cal} / \mathrm{cm}^{3}-\mathrm{C}\right)$ & $\mathrm{C}_{\mathrm{s}}$ & 0.239 & Bastola and Peterson (2016) \\
\hline Volumetric heat capacity of water $\left(\mathrm{cal} / \mathrm{cm}^{3}-\mathrm{C}\right)$ & $\mathrm{C}_{\mathrm{w}}$ & 1 & Lapham (1989) \\
\hline
\end{tabular}

The above hydraulic and material parameters represent the Henry formation, comprising the LKC study site. These parameters are used as initial inputs in VFLUX.

As water moves through the hyporheic zone, two distinct things occur to the thermal signature at an increasing depth: A time delay (phase shift) and a temperature reduction (amplitude dampening) (Fig. 4). The conduction-advection-dispersion equation has been modified to factor in amplitude and the periodic frequency of temperature fluctuations within the streambed (Stallman, 1965; Goto, 2005). This equation is divided into two components: amplitude dampening and a phase shift component (Hatch et al., 2006). The phase shift can be used to calculate vertical flow but will render a scalar value (magnitude) and does not give a direction of flow. McCallum et al. (2012) and Luce et al. (2013) found that the phase shift method had a higher amount of uncertainty than the amplitude ratio method for downwelling conditions. Amplitude can then be used to calculate a magnitude and direction of vertical flow. The Amplitude method is used in this study to calculate the direction and magnitude of vertical flow. A 1-D flux rate is calculated by solving for the ratio of amplitude variation, Ar, between two temperature profiles when homogenous streambed material is assumed (Hatch et al., 2005). $A_{r}=\exp \left\{\frac{\Delta z}{2 K_{e}}\left(v-\sqrt{\frac{\alpha+v^{2}}{2}}\right)\right\}$ 


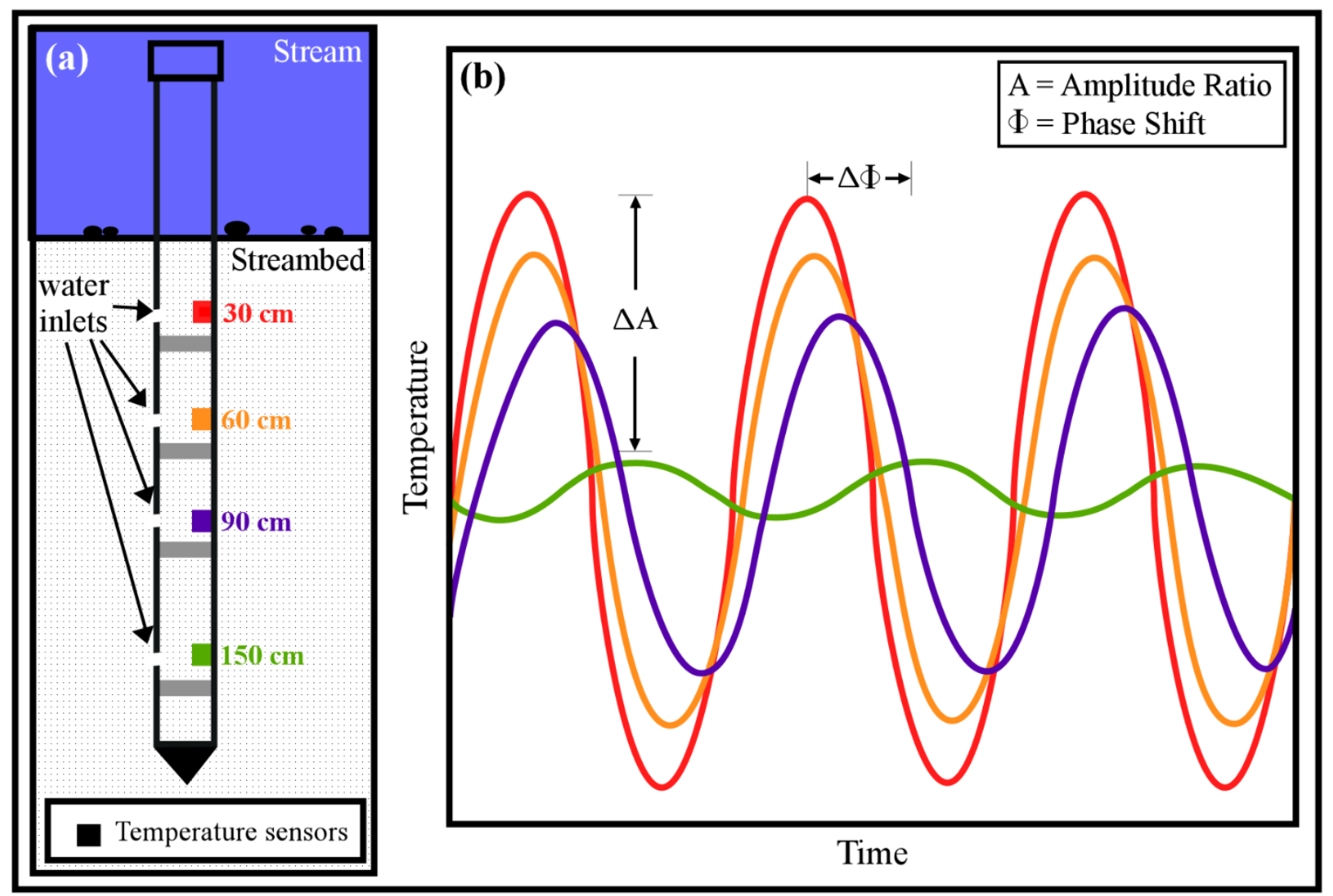

Fig. 4 a). Phase shift and amplitude dampening of thermal signals with increasing depth. A nested streambed well with four temperature sensors at increasing depths. Each temperature sensor was isolated with foam sealant. b) Amplitude attenuation of sinusoidal temperature signals with changes in depth. The amplitude of thermal signals decreases, $\Delta A$, and the signal is delayed, shift in phase $(\Delta \phi)$, with increasing depth in the streambed (graphic modified from Hatch et al., 2006).

The rate of penetration of thermal front $\left(v=v_{f} / \gamma\right)$ is proportional to the fluid velocity $\left(v_{f}\right)$ and inversely proportional to the ratio of the volumetric heat capacity of the streambed to the volumetric fluid heat capacity $\left(\gamma=\mathrm{C}_{\mathrm{s}} / \mathrm{C}_{\mathrm{w}}\right)$. The alpha, $\alpha$, term is dependent on thermal 
diffusivity $\left(\mathrm{K}_{\mathrm{e}}\right)$, thermal front velocity $(\mathrm{v})$, and the period of temperature variations, $\mathrm{P}=$ frequency ${ }^{-1}$.

$\alpha=\sqrt{v^{4}+\left(\frac{8 \pi * K_{e}}{P}\right)^{2}}$

Equation 2 uses $\Delta \mathrm{z}$ to represent the spacing between the two temperature sensors. This method is applied at the midpoint of each temperature sensor pair at all six wells in the streambed. The VFLUX method evaluates flux between sensor spacings and not the absolute depths of the temperature sensors (Hatch et al., 2006). It limits the sensitivity of the forward model produced by Hatch to streambed scour or sediment buildup (Hatch et al., 2006).

The automated toolbox VFLUX utilizes the forward model produced by Hatch et al. (2006) to calculate a thermal front velocity with the following equation (Gordon et al., 2012; Irvine et al., 2015):

$v=\left(\frac{2 K_{e}}{\Delta z} \ln A_{r}+\sqrt{\frac{\alpha+v^{2}}{2}}\right)$

The 1-D vertical flux has the following relationship with the thermal front velocity $(v)$ and the ratio of the heat capacity of the streambed to the volumetric fluid heat capacity $\left(\mathrm{C}_{\mathrm{s}} / \mathrm{C}_{\mathrm{w}}\right)($ Gordon et al., 2012; Irvine et al., 2015):

$q=\frac{C_{s}}{C_{w}} v$

The thermal front velocity appears explicitly on both sides of equation 4 and implicitly in $\alpha$, therefore it is solved for iteratively. VFLUX subtracts q from both sides of the equation for and solves for the root value of $\mathrm{q}$ at which the left side of the equation equals.

The VFLUX model makes various assumptions about the flux calculations: fluid flow is one-dimensional in the vertical direction, there is a sinusoidal temperature signal, there is no mean thermal gradient present in the streambed with depth, and the streambed is homogenous 
(Irvine et al., 2015). The model manages the data, resamples the data, extracts the diurnal signal using a dynamic harmonic regression, and calculates a vertical flux (Gordon et al., 2012; Irvine et al., 2015). The VFLUX script will resample the temperature time series to 12 samples per day to limit issues of oversampling. After the program resamples the data, a DHR regression isolates the fundamental diurnal temperature signal (Young et al., 1999). The DHR filter utilizes the CAPTAIN toolbox (Young et al. 1999; Young et al., 2010). Finally, the VFLUX function calculates flux with the following inputs: temperature profiles at depth, sensor depths, period of fundamental temperature signal, total porosity, thermal dispersivity of the streambed, thermal conductivity of the streambed, volumetric heat capacity of the sediment, and volumetric heat capacity of the water (Gordon et al., 2012; Irvine et al., 2015). The amplitude is a calculated variable that the model extracts from the temperature signal input (Gordon et al., 2012; Irvine et al., 2015).

The sensitivity of the heat transfer model (VFLUX) is tested with incremental changes in porosity (n), thermal dispersivity $(\beta)$, baseline thermal conductivity in the absence of fluid flow $\left(\lambda_{\mathrm{o}}\right)$, the linear fluid velocity, and the volumetric heat capacity of the streambed $\left(\mathrm{C}_{\mathrm{s}}\right)$. Flux is calculated with high and low values of each parameter while keeping the other parameters at their initial values. Each parameter is incrementally adjusted by $20 \%$ change with a maximum percent change of $40 \%$ bounding the initial values. The initial input values for flux calculations are in table 1 , and the sensitivity analysis is performed on well 1 at the $15 \mathrm{~cm}$ midpoint. The sensitivity of the model to each parameter is determined by the mean absolute error.

\section{Statistics: Stage and Vertical 1-D Flux}

I hypothesized that there would be a negative linear relationship between stage and flux; If stage rises, the stream will be in a losing condition (negative flux) and if the stage decreases, 
the stream will be in a gaining condition (positive flux). The Spearman's rank correlation coefficient was used to describe the strength of the bivariate relationship between calculated flux and stage. The Spearman's rank correlation was use chosen due the non-normal distribution of the data. The Spearman's rank coefficient of flux and stage was calculated in the R Statistical Environment (Team, R. C., 2014). The null hypothesis, no statistically significant linear correlation between stage and flux, is tested with a critical significance level of 0.05 . A twotailed test was chosen to see if there was a negative or positive correlation between stage and 1-D Vertical fluxes.

With the assumption that a change in stage will not induce an instantaneous change in flux, the correlation between stage and flux is measured with a displacement or lag in flux. The strength in the relationship between stage and flux is calculated with forward temporal lags in the calculated flux at six wells at each corresponding sensor pair midpoint: $15 \mathrm{~cm}, 45 \mathrm{~cm}, 75 \mathrm{~cm}$, and $120 \mathrm{~cm}$. A script in the R Statistical Environment was written to use the Spearman's rank coefficient to assess the strength of the relationship between stage and the shifted flux variable converted into ordinal values. The calculated flux variable was shifted forward to a maximum of 80 hours with a temporal resolution of two hours. The relationship between stage and 1-D vertical flux is evaluated at each 2-hour lag of calculated flux. The result is the lag time that renders the highest correlation coefficient between the bivariate relationship. The crosscorrelation tests was two-tailed with a critical significance level of 0.05 . 


\section{CHAPTER IV: RESULTS}

\section{Trends in Raw Temperature Data and Vertical 1-D Flux}

Throughout the time series the average stage is 221.41 meters above mean sea level (m.a.m.s.l) and ranges from a 220.98 to 223.71 m.a.m.s.l (Fig. 5). Stage is lowest in the summer compared to spring, winter, and fall. Baseflow is lowest in the summer and spring and is higher in the fall and winter. Precipitation is dominant during the spring, summer, and fall. Winter received less precipitation relative to summer, but the recession curves are larger in both magnitude and duration. The summer storms have a lower peak flow reaching baseflow equilibrium faster than the beginning of summer (May-July), fall, and winter.

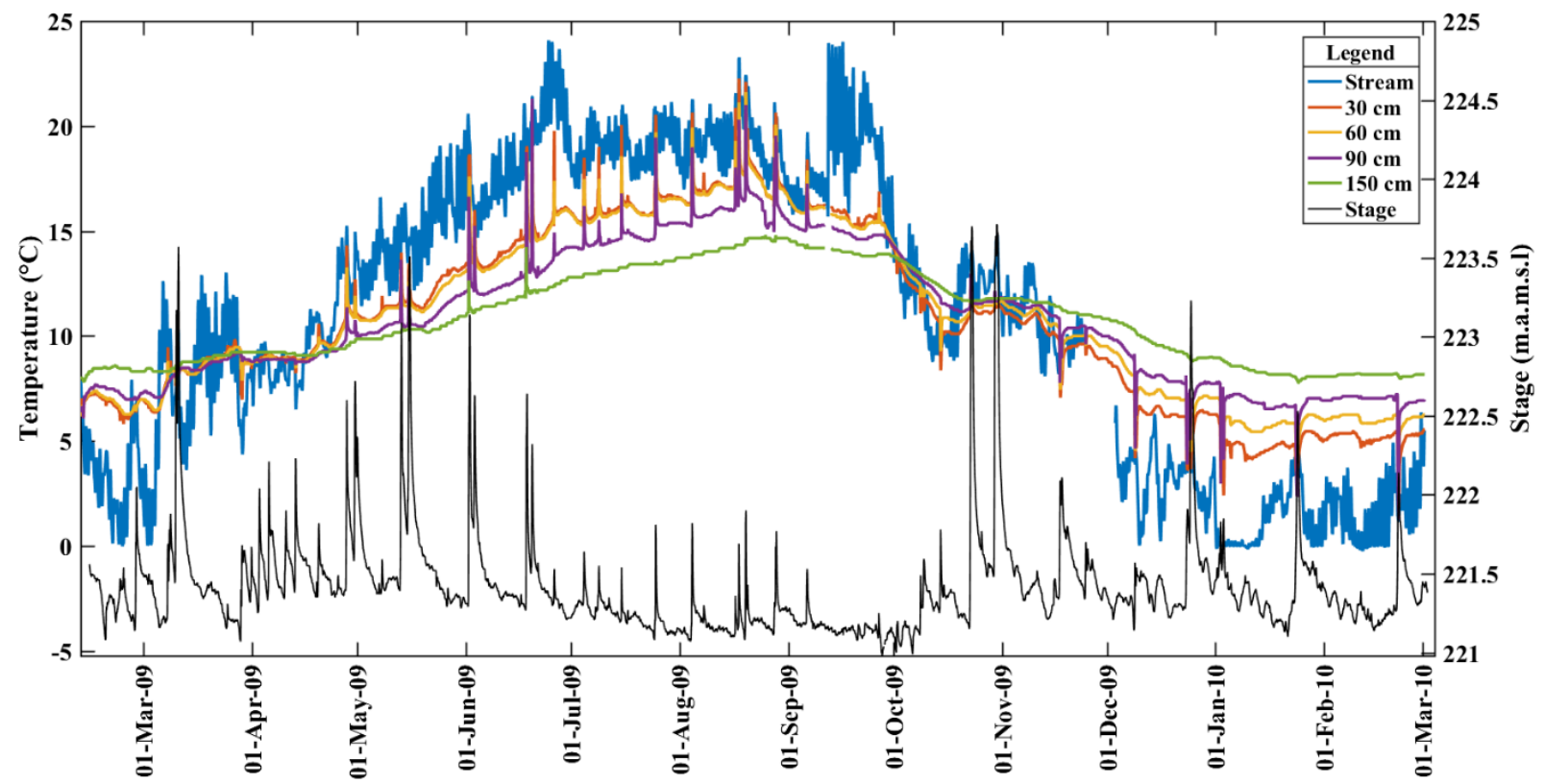

Fig. 5 Well 1 temperature in stream, 30, 60, 90, and $150 \mathrm{~cm}$ depth with stage time series. Well 1 is the farthest upstream and representative of all six wells. 
The 13-month stream temperature time series follows a sinusoidal curve with a maximum temperature of $24.08{ }^{\circ} \mathrm{C}$ in June and a minimum of $-0.23{ }^{\circ} \mathrm{C}$ in February (Fig. 5). A diurnal sinusoidal signature overlays the annual sinusoidal signal with an average daily temperature change of $2.11^{\circ} \mathrm{C}$. There are three apparent temporal trends in the raw 13-month temperature time series at depth for all six wells along LKC (Fig. 5): temperature decreases with depth, temperature increases with depth, and temperature is homogenous with changing depth. The six wells show similar thermal patterns; thus, well 1 is used as a representative sample to show recurring trends in the raw temperature time series (Fig. 5). The summer (May - October) and winter (April 2009 and December-March 2010), exhibit a temperature difference between the stream and groundwater. In the summer and winter, the deeper hyporheic zone water is moderated by the upwelling surface water compared to the influence of the surface water in the shallow depths. The summer (May - October) and winter have average daily stream temperature fluctuations of $2.39{ }^{\circ} \mathrm{C}$ and $1.74{ }^{\circ} \mathrm{C}$. Despite average daily temperature fluctuations of $2.48{ }^{\circ} \mathrm{C}$, spring (March-May), and $1.62^{\circ} \mathrm{C}$, fall (October - December), that are similar in magnitude to the summer and winter, the temperature profile (stream, $30 \mathrm{~cm}, 60 \mathrm{~cm}, 90 \mathrm{~cm}, 150 \mathrm{~cm}$ ) is relatively homogenous during these periods. The similarity of the surface water and groundwater temperatures in the spring and fall masks the influence of either source, groundwater or surface water, in the streambed temperature. The homogeneity of the streambed temperature with depth inhibits a strong propagation of a diurnal signal.

The temperature time series has two temperature gradient inflection points occurring at the onset of summer and winter (May and October). Spring and fall exhibit homogenous 
temperatures with depth, resulting in temperature gradients with small fluctuations. In 2009, the spring temperature gradient (stream to $150 \mathrm{~cm}$ ) ranges from -0.038 to $0.056^{\circ} \mathrm{C} / \mathrm{cm}$ with an average of $0.0025^{\circ} \mathrm{C} / \mathrm{cm}$. The fall displays a similar trend of shifting temperature gradients ranging from -0.020 to $0.025^{\circ} \mathrm{C} / \mathrm{cm}$ with an average of $0.004{ }^{\circ} \mathrm{C} / \mathrm{cm}$. The summer season reveals a high negative temperature gradient compared to the spring, fall, and winter ranging from 0.078 to $-0.002{ }^{\circ} \mathrm{C} / \mathrm{cm}$ with an average of $-0.035^{\circ} \mathrm{C} / \mathrm{cm}$. The 2009 winter season (February 2009) shows a positive temperature gradient ranging from 0.003 to $0.057^{\circ} \mathrm{C} / \mathrm{cm}$ with an average of $0.035^{\circ} \mathrm{C} / \mathrm{cm}$. Lastly, the 2010 winter season (December to March 2010) presents a similar positive temperature gradient that ranges from 0.012 to $0.067^{\circ} \mathrm{C} / \mathrm{cm}$ with an average of 0.045 ${ }^{\circ} \mathrm{C} / \mathrm{cm}$. Summer and winter have average temperature gradients an order of magnitude larger than spring and fall. Summer and winter have opposing temperature gradients (negative and positive) with similar magnitudes.

Across all seasons, the stream temperature has a diel signal that does not propagate to a streambed depth of $150 \mathrm{~cm}$ (Fig. 5; Fig. 6). The amplitude averages for each season at each temperature sensor depth are in Table 2. The average temperature amplitude at $150 \mathrm{~cm}$ depth is 0.00 for each season (Table 2). Amplitudes decrease with increasing depth with an extinction between 90 to $1500 \mathrm{~cm}$ depth. The 2009 winter, summer, fall, and winter 2010 have diel signals down to $90 \mathrm{~cm}$ depth. In the spring, the diel signature is extinct at $90 \mathrm{~cm}$ (Table 2). The entire time series has an average amplitude of 0.02 down to $90 \mathrm{~cm}$ depth. The streambed temperature signals at depths of 30,60 , and $90 \mathrm{~cm}$ are influenced by diel variations in stream temperature that propagate through the streambed as dampened signals (Fig. 7). During storm events occurring in periods of positive and negative temperature gradients, the surface temperature signal is extinct by $150 \mathrm{~cm}$ (Fig. 7). Oware (2010) provides an analysis of thermal transport during storm events 
in $\mathrm{LKC}$, and readers are directed there for more explanation. In the winter, the pre-storm substrate temperature increases with depth. Oware (2010) found rapid advective heat transport up to $60-90 \mathrm{~cm}$ with a large amplitude response as storm wetting fronts passed through the stream. A small amplitude between $90-150 \mathrm{~cm}$ delineates the groundwater transition zone. The thermal inertia of the deeper substrate creates slower transmission rates.

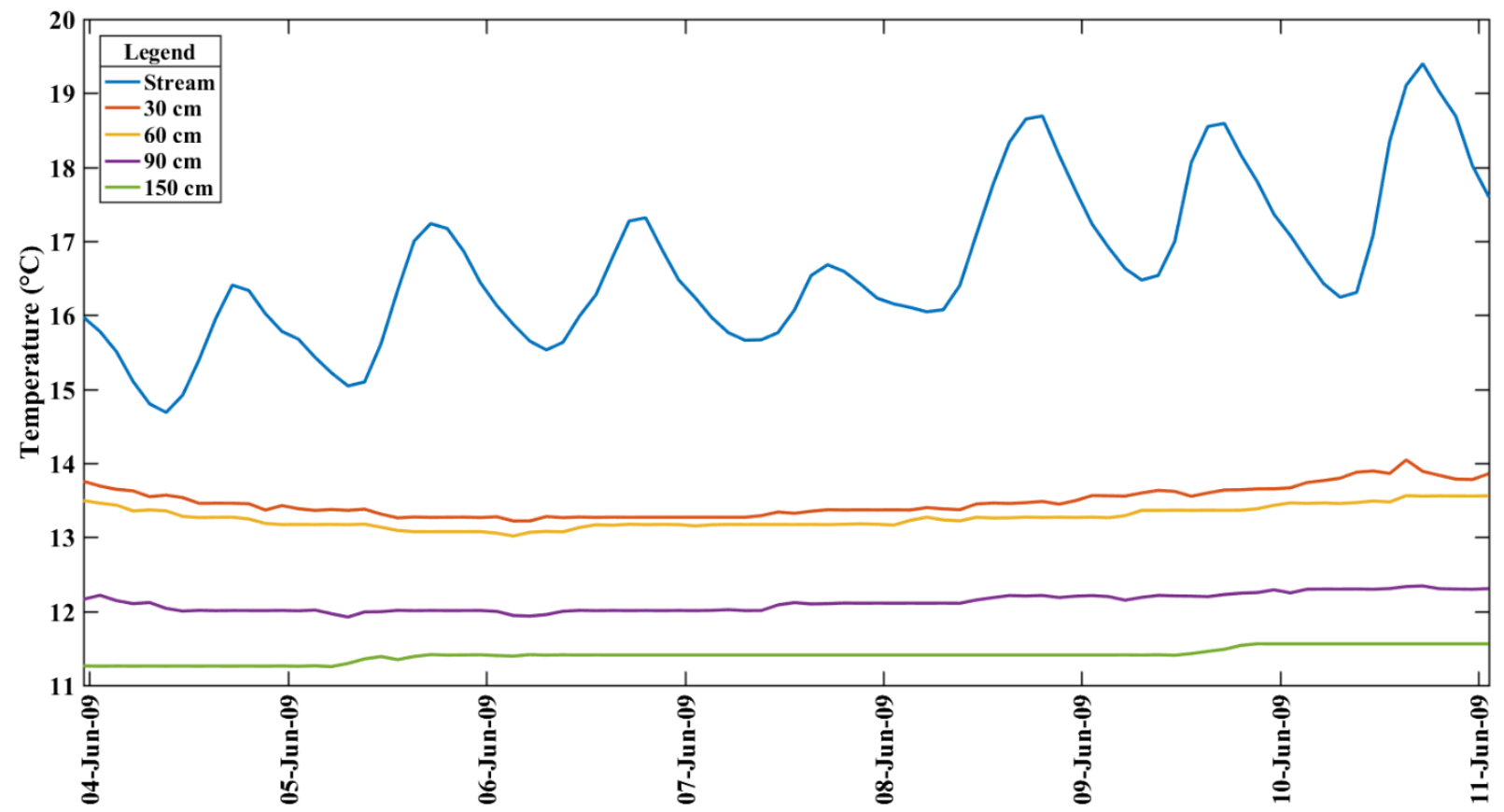

Fig. 6 Week-long temperature time series at 30, 60, 90, $150 \mathrm{~cm}$ depth. There is a weak propagation of the diurnal stream temperature signal into the streambed temperature signals. The stream temperature signature is extinct at $150 \mathrm{~cm}$ depth. 
Table 2 Seasonal amplitude averages for 30, 60, 90, $150 \mathrm{~cm}$ depths.

\begin{tabular}{|c|c|c|c|c|c|c|}
\hline Depth $(\mathrm{cm})$ & $\begin{array}{c}\text { Complete Time Series Min, } \\
\text { Mean, Max Amplitude } \\
\left({ }^{\circ} \mathrm{C}\right)\end{array}$ & $\begin{array}{c}\text { Winter 2009 } \\
\text { Mean Amplitude } \\
\left({ }^{\circ} \mathrm{C}\right)\end{array}$ & $\begin{array}{c}\text { Spring } \\
\text { Mean Amplitude } \\
\left({ }^{\circ} \mathrm{C}\right)\end{array}$ & $\begin{array}{c}\text { Summer } \\
\text { Mean Amplitude } \\
\left({ }^{\circ} \mathrm{C}\right)\end{array}$ & $\begin{array}{c}\text { Fall } \\
\text { Mean Amplitude } \\
\left({ }^{\circ} \mathrm{C}\right)\end{array}$ & $\begin{array}{c}\text { Winter 2010 } \\
\text { Mean Amplitude } \\
\left({ }^{\circ} \mathrm{C}\right)\end{array}$ \\
\hline Stream & $0.02,0.82,2.59$ & 0.86 & 0.91 & 0.99 & 0.60 & 0.62 \\
\hline 30 & $0.00,0.03,0.07$ & 0.01 & 0.02 & 0.03 & 0.03 & 0.04 \\
\hline 60 & $0.00,0.02,0.05$ & 0.01 & 0.01 & 0.02 & 0.03 & 0.03 \\
\hline 90 & $0.00,0.02,0.13$ & 0.01 & 0.00 & 0.02 & 0.01 & 0.06 \\
\hline 150 & $0.00,0.00,0.00$ & 0.00 & 0.00 & 0.00 & 0.00 & 0.00 \\
\hline
\end{tabular}

The DHR model isolates the diurnal signal and calculates the amplitude of the thermal signal every 2 hours (Young et al. 1999; Young et al., 2010). The diurnal signal is weakly present up to $90 \mathrm{~cm}$ and absent at $150 \mathrm{~cm}$. The amplitude decreases with increasing depth in all seasons except for winter 2010 .
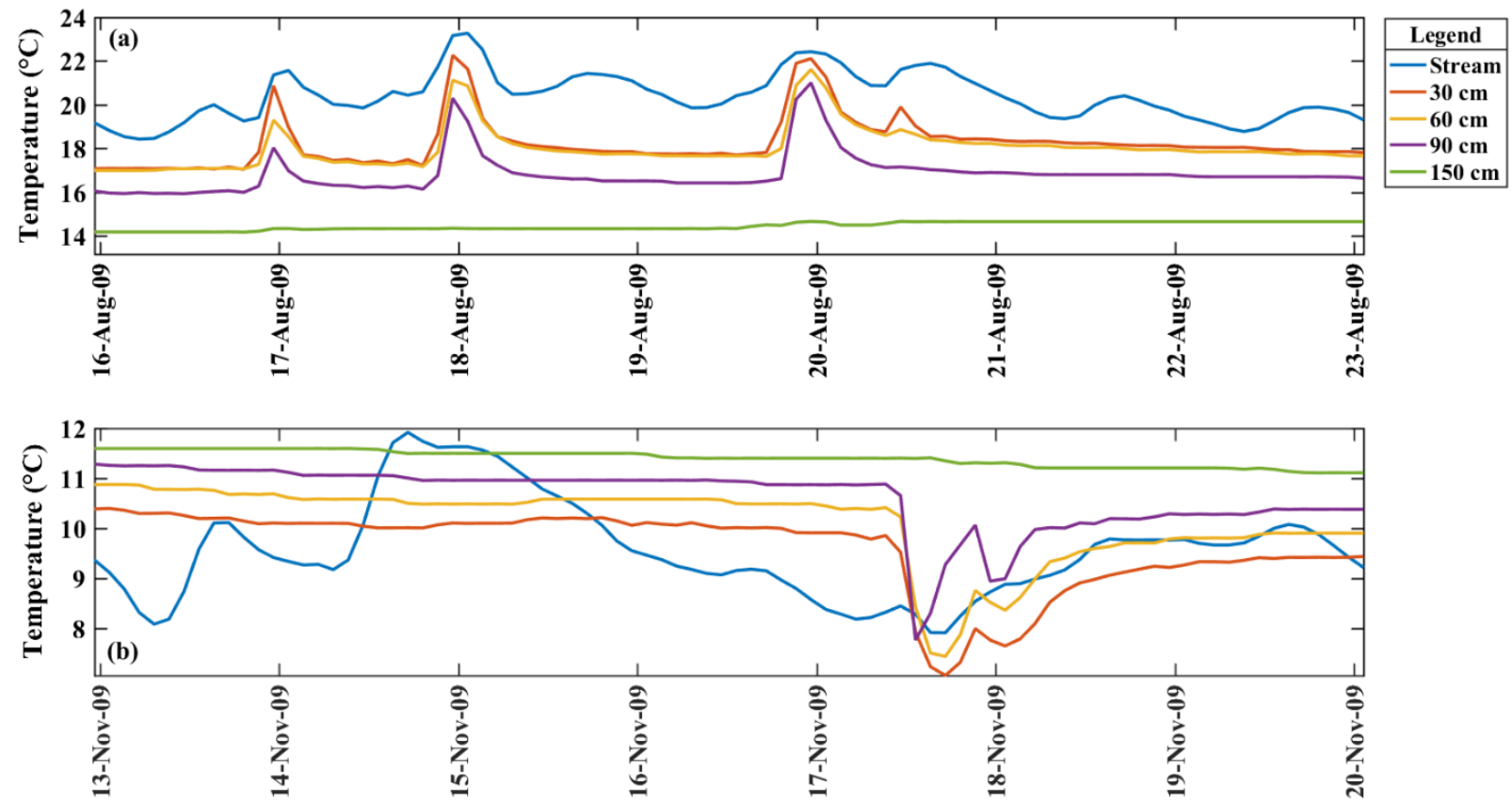

Fig. 7 Week-long temperature time series with storm events at 30, 60, 90, $150 \mathrm{~cm}$ depth. There are storm events on $8 / 17,8 / 18,8 / 20$, and $11 / 17-11 / 19$. The summer temperature gradient is negative (a), and the winter is positive (b). The stream temperature signal change during the storm event propagates down to a streambed depth of $90 \mathrm{~cm}$ in the winter and summer. 
The raw temperature time series was filtered using the Dynamic Harmonic Regression model (Young et al. 1999; Young et al., 2010) to extract the fundamental temperature signal used to calculate fluxes at each sensor midpoint (Fig. 8). The time series was resampled to a temporal resolution of 2 hours. The calculated vertical flux reveals an increasing variation in magnitude with increasing depth (Fig. 9). Flux is relatively stable at a depth of $15 \mathrm{~cm}$ when compared to the $45 \mathrm{~cm}, 75 \mathrm{~cm}$, and $120 \mathrm{~cm}$ midpoint. The shallow sub-surface $(15 \mathrm{~cm})$ has a dominantly negative flux (Fig. 9; Fig. 10). Negative flux indicates downward movement into the streambed, and positive flux specifies upward movement towards the stream. The flux direction is upward (positive flux) at the $45 \mathrm{~cm}, 75 \mathrm{~cm}$, and $120 \mathrm{~cm}$ midpoints. At $45 \mathrm{~cm}$ and below, the magnitude of flux is highly variable with high-frequency spikes and missing calculations. The missing flux values occur when the VFLUX program rejects calculations due to the amplitude ratio being greater than 1 , or the program failing to converge on a root value of the thermal front velocity (Equation 4; Hatch et al., 2006; Gordon et al., 2012). Values of Ar that are too low or high $(0 \leq$ Ar $\geq 1$ ) result in significant errors in calculated flux (Hatch et al., 2006; Gordon et al., 2012). The miscalculations can be a result of a missing solar component (diel surface signal) at depth or the sensor spacing being too large (Hatch et al., 2006; Gordon et al., 2012). The deeper sensor pairs $(45 \mathrm{~cm}$ and $75 \mathrm{~cm}, 90 \mathrm{~cm}$ and $150 \mathrm{~cm}$ ) do not have sufficient surface diurnal signals resulting in too small of amplitudes. The transmission of the diurnal signal is weak at depths below $15 \mathrm{~cm}$, and the streambed temperatures do not create an amplitude difference large enough (amplitude ratio approaching 1) to provide appropriate and reliable flux calculations throughout the time series. While the stream temperature signal weakens with increasing depth, it is still present up to $90 \mathrm{~cm}$ of depth (Table 2). Flux at $15 \mathrm{~cm}$ is filtered to where Ar $\geq 0.9$, filtering out 
less than $1 \%$ of the fluxes (Fig. 10). Across all six streambed wells, the percentage of $\mathrm{Ar} \geq 0.9$ at depths of 45,75 , and $90 \mathrm{~cm}$ is $4.54 \%, 17.82 \%$, and $35.85 \%$.

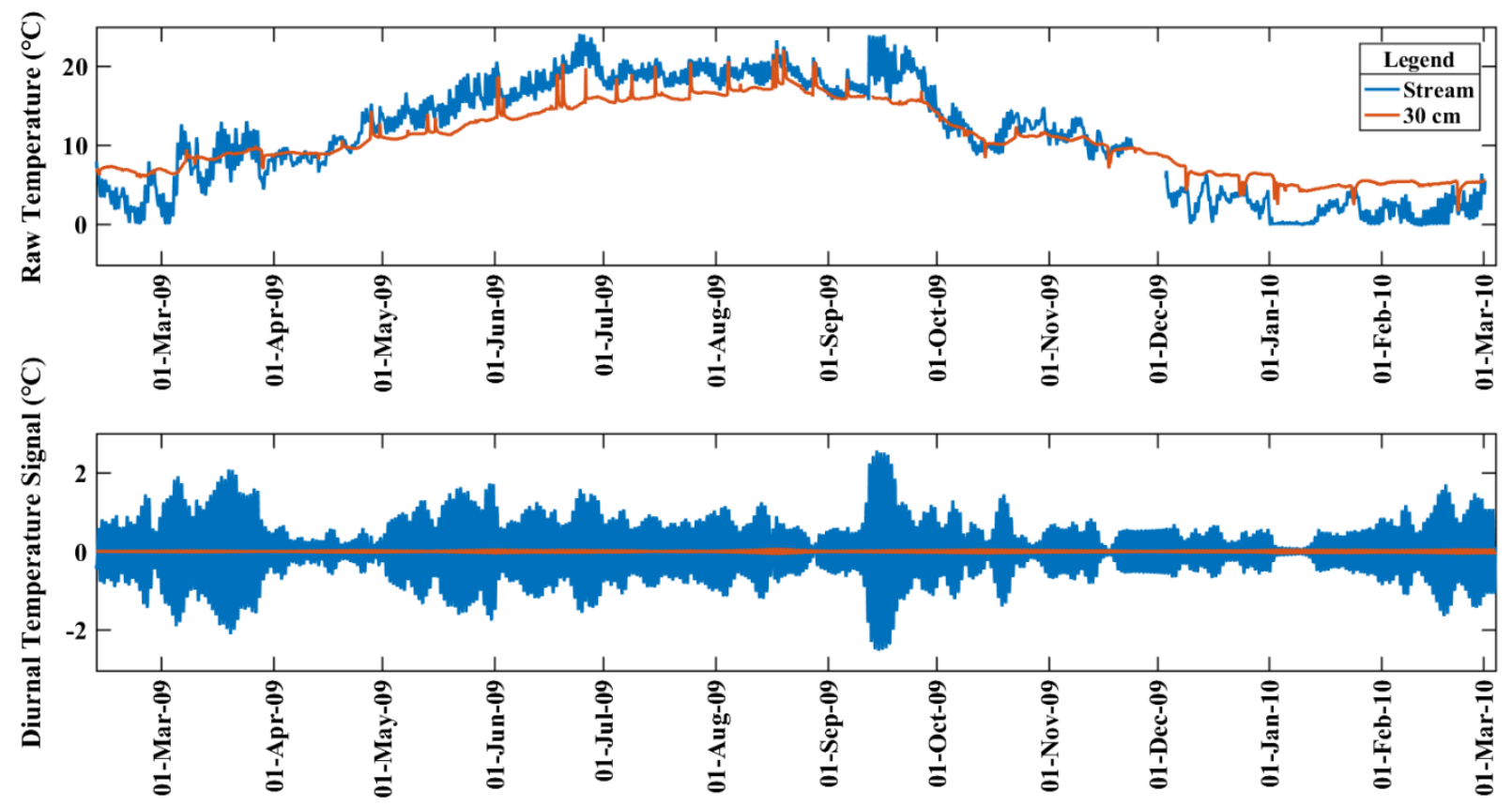

Fig. 8 a) Complete 13-month raw temperature time series. b.) The diurnal (24-hour) component isolated from the raw temperature time signal by the DHR model (Young et al. 1999; Young et al., 2010). The amplitude variation is minimal at a depth of $30 \mathrm{~cm}$. The amplitude decreases with increasing depth. 


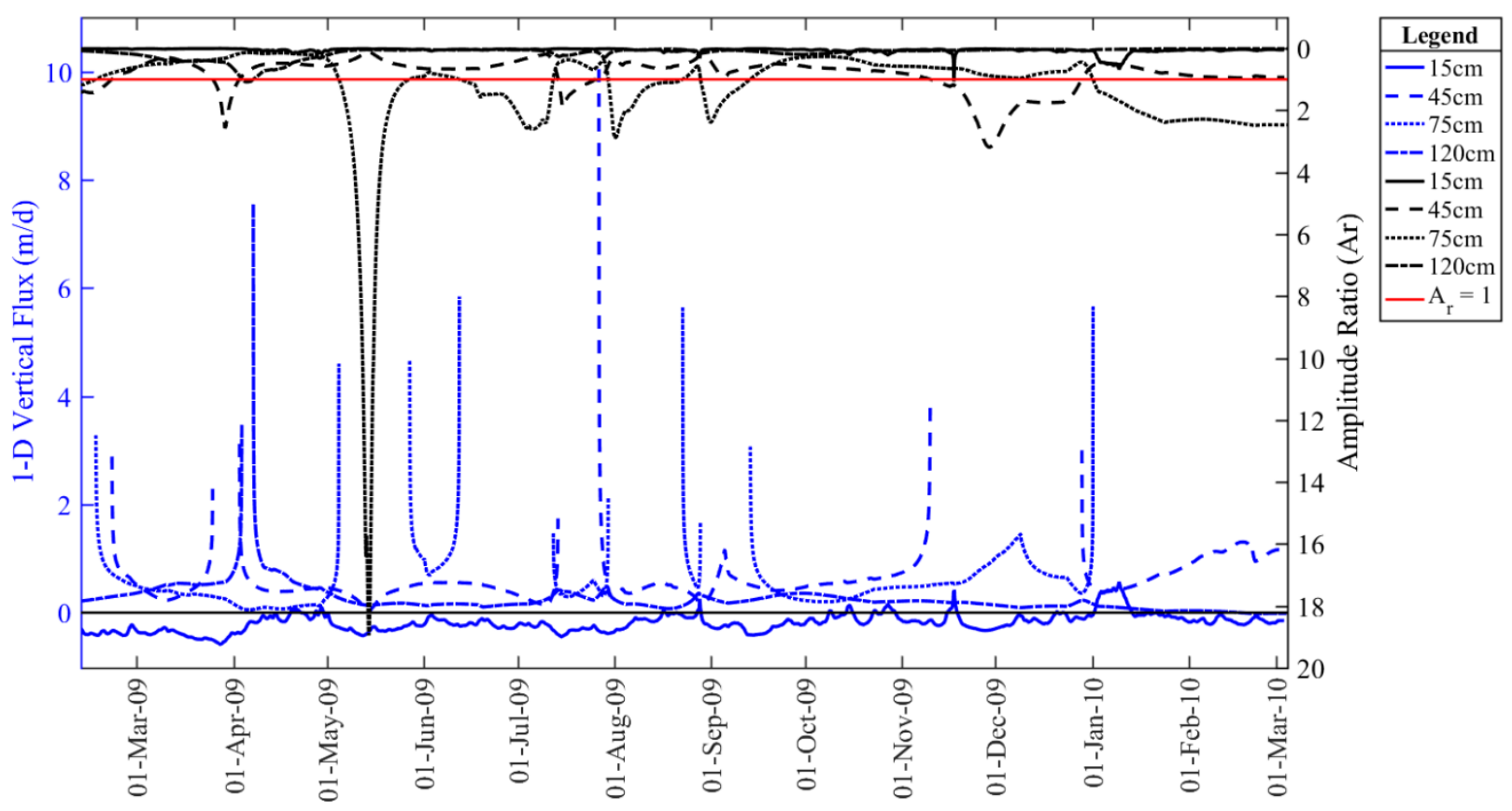

Fig. 9 Well 1 calculated 1-D vertical flux (blue) and amplitude ratio (Ar) (red). Spikes in flux occur when the Ar approaches 1 and the missing flux calculations occur when the Ar $\geq 1$. The flux values are from well 1 and are representative of all six wells. 

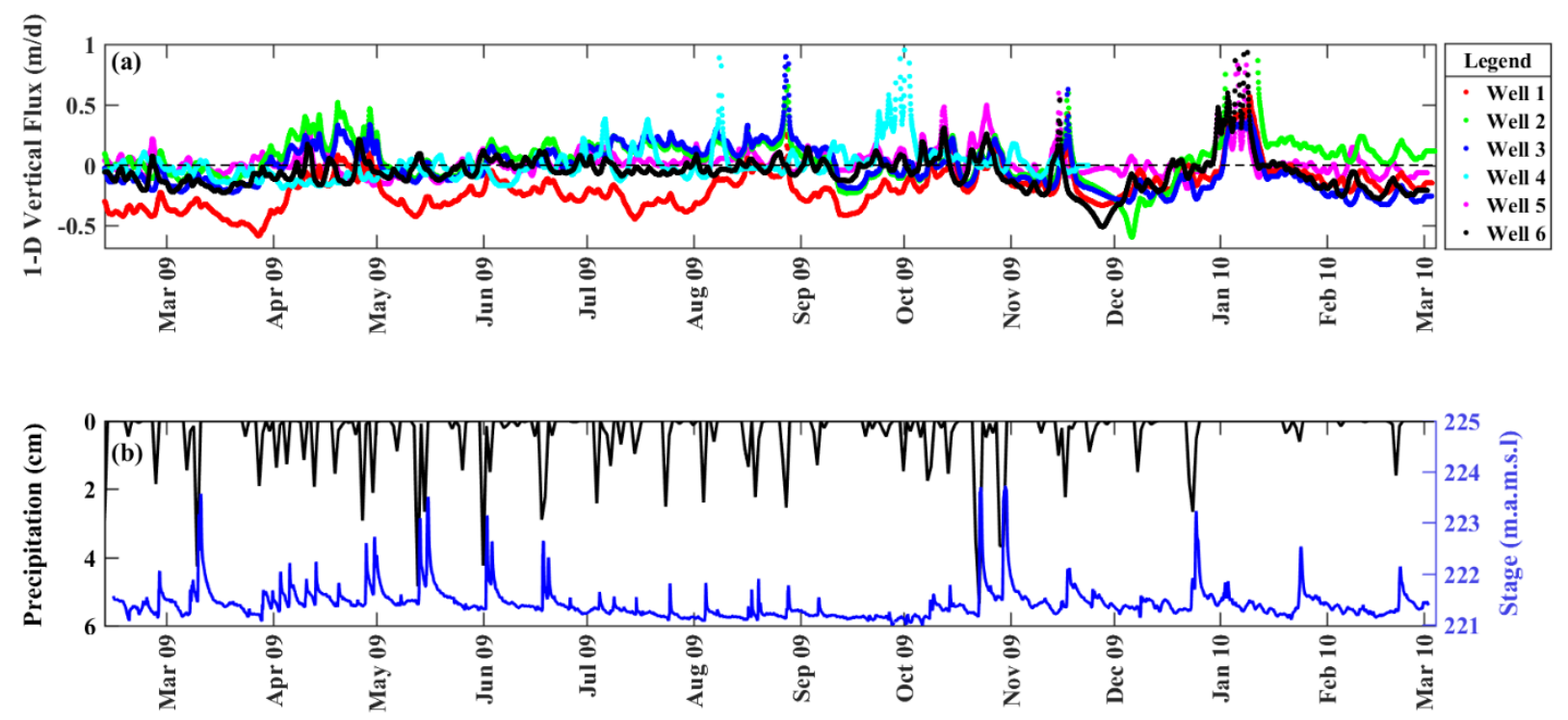

Fig. 10 a). Calculated Flux at $15 \mathrm{~cm}$ depth for all six wells. b). Raw precipitation and stage data. Stage is lowest in the summer (May-July) when flux rates are higher relative to fall, winter, and spring.

Although the diurnal signal is not strongly propagating to $150 \mathrm{~cm}$ depth, advective heat transfer is present across the entire streambed profile at depths of $15,45,75$, and $120 \mathrm{~cm}$.

Thermal advection is the dominant heat transfer mechanism at all depths. Peclet numbers (Pe) the ratio of heat advection to conduction, indicate advective transport throughout the hyporheic zone:

$P e=\frac{C_{w} * q * l}{\lambda_{o}}$

Peclet numbers are dependent on the length of the spacing between temperature sensors $(l)$.

Peclet numbers equal to 1 imply an equal abundance of conduction and advection, a Pe $>1$

signifies that advection is dominant, and $\mathrm{Pe}<1$ implies that conduction is that dominant heat transfer mechanism. Seasonal Peclet numbers were calculated for Well 1 at each midpoint (Table 
3). The Peclet numbers were calculated with fluxes that have a corresponding amplitude ratio $<=$ 0.9 (Table 3). Peclet numbers generally increase with increasing depth across all seasons indicating the increasing dominance of heat advection with increasing depth in the hyporheic zone (Table 3).

Table 3 Average Seasonal Peclet numbers (Pe) at each midpoint depth.

\begin{tabular}{|c|c|c|c|c|c|c|}
\hline & \multicolumn{6}{|c|}{ Peclet Values $(\mathrm{Pe})$} \\
\hline Depth $(\mathrm{cm})$ & Winter 2009 & Spring 2009 & Summer 2009 & Fall 2009 & Winter 2010 & Average \\
\hline 15 & 3.85 & 2.92 & 2.51 & 1.63 & 1.58 & 2.50 \\
\hline 45 & 7.38 & 4.50 & 4.46 & 6.58 & 1.62 & 4.91 \\
\hline 75 & 6.89 & 2.42 & 5.32 & 4.77 & 6.75 & 5.23 \\
\hline 120 & 6.10 & 12.18 & 4.44 & 4.75 & 1.59 & 5.81 \\
\hline
\end{tabular}

Averages were calculated using all six streambed wells. The Pe values are calculated using flux values that have corresponding amplitude ratios $<=0.9$.

The heat transfer model is most sensitive to thermal conductivity followed by porosity and volumetric heat capacity (Fig. 11). The VFLUX model is least sensitive to dispersivity. The average flux rate at the $15 \mathrm{~cm}$ midpoint at well 1 is $0.19 \mathrm{~m} / \mathrm{d}$. Flux rates can change up to 0.15 $\mathrm{m} / \mathrm{s}$ with a $40 \%$ change in thermal conductivity. Thermal conductivity can significantly alter flux rates, but it is important to note that changes in thermal conductivity will change the magnitude of flux, but the direction of flux will be consistent with a percent change in thermal conductivity. This paper aims to focus on the overall temporal trends in flux. The initial thermal conductivity value of $0.0033 \mathrm{cal} / \mathrm{sec}-\mathrm{cm}-\mathrm{C}$ was used in the summer and winter best-fit VS2DH numerical model for Little Kickapoo Creek using the same data as this study (Bastola and Peterson, 2016). The VS2DH spring best-fit model used a higher thermal conductivity value of $0.0059 \mathrm{cal} / \mathrm{sec}-$ 
cm-C (Bastola and Peterson, 2016). The lower thermal conductivity value was chosen for this study as it fits more of the seasons in the VS2DH model and it allowed for underestimation versus an overestimation of thermal conductivity. Thermal conductivity is directly proportional to flux, implicit in thermal diffusivity (Eq. 2; Eq. 5). Porosity and volumetric heat capacity have an error in flux of 0.04 and $0.02 \mathrm{~m} / \mathrm{d}$ with a $40 \%$ change in either parameter, which is an order of magnitude smaller than the average flux rate at well 1 . The initial porosity and volumetric heat capacity values were obtained from Bastola and Peterson (2016) best-fit models. The heat transfer model is least sensitive to dispersivity with a change less than $0.1 \mathrm{~m} / \mathrm{d}$ with a $40 \%$ percent change in the parameter. 


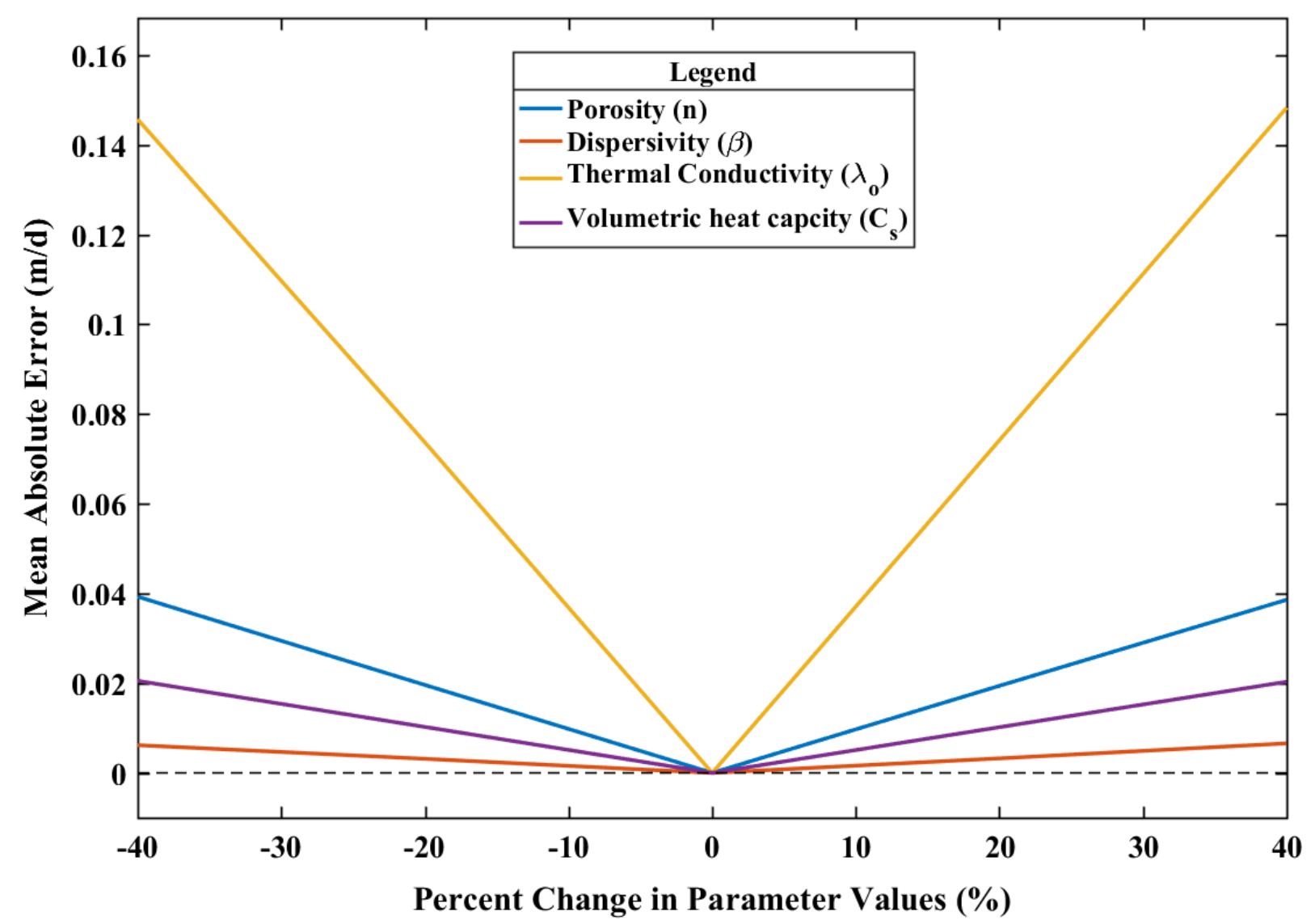

Fig. 11 Sensitivity analysis for independent variables used in flux calculations. The graph shows the changes in flux with the corresponding changes in thermal and material parameters at a depth of $15 \mathrm{~cm}$ for well 1.

\section{Correlation of Stage and 1-D Flux}

The fluxes at the $15 \mathrm{~cm}$ midpoint for all six wells ranges between -0.59 to $0.95 \mathrm{~m} / \mathrm{d}$ with an average of $-0.04 \mathrm{~m} / \mathrm{d}$ (Fig. 10A). The average flux for the $15 \mathrm{~cm}$ midpoint during winter 2009, spring 2009, summer 2009, fall 2009, and winter 2010 seasons are as follows: $-0.09,-0.06,-0.02$, -0.04 , and $-0.05 \mathrm{~m} / \mathrm{d}$. Throughout the 13 -month time series, the $15 \mathrm{~cm}$ depth water is moving downward on average, but there is a temporal variation in flux seen in Fig. 10. The stream hovers 
around a flux of zero transitioning between gaining and losing stream conditions. In the summer, the average flux at a midpoint depth of $15 \mathrm{~cm}$ is low compared to the other seasons.

Qualitatively, there is near-surface upwelling when stream stage is low (Summer 2009) and downwelling when stage is high (Spring 2009, Fall 2010, and Winter 2010) (Fig. 10B).

Quantitatively, there is a significant, but weak correlation between flux and stage at the $15 \mathrm{~cm}$ depth (Table 4).

The strength of the bivariate relationship between stage and flux in the near-surface streambed $(15 \mathrm{~cm})$ was analyzed using a two-tailed Spearman's rank correlation test. The Spearman's correlations for all six wells at $15 \mathrm{~cm}$ are very weak (Table 4). Four of the wells have a positive relationship and two exhibit a negative correlation. A negative correlation represents stage rising and flux magnitude increasing in the negative direction (losing stream condition) and vice versa. A positive correlation implies that as stage rises, flux increases in the positive or upward direction (gaining stream condition). The highest Spearman's coefficient magnitude is 0.369 for well 4 . Wells 1, 2, 3, 5, and 6 each have correlations less than or equal to 0.15 (Table 4).

A cross-correlation analysis of stage and incremental lags in flux was interpreted using Spearman's rank correlation (Table 4). Correlations of stage and lagged flux were calculated by keeping stage stagnant in time, while flux was temporally shifted forward with a resolution of 2 hours. The max correlation between stage and flux within an 80-hour window is included in the second row of table 4. The Spearman's rank correlations have p-values that are statistically significant, but very weak correlations for all six wells. There is no apparent trend in the lag time for the maximum correlation between stage and flux at the $15 \mathrm{~cm}$ midpoint. Half of the 80-hour window maximum correlations are negative, and the other half are positive. The highest 
magnitude Spearman's coefficient magnitude is 0.442 at well 4 . The other five wells have a Spearman's coefficient less than 0.20 .

Table 4 Spearman's Rank Correlation coefficients $(\rho)$ for all six wells at $15 \mathrm{~cm}$ midpoint depth.

\begin{tabular}{|c|c|c|c|c|c|c|c|c|c|c|c|c|}
\multicolumn{2}{|c|}{ Well 1 } & \multicolumn{2}{c|}{ Well 2 } & \multicolumn{2}{c|}{ Well 3 } & \multicolumn{2}{c|}{ Well 4 } & \multicolumn{2}{c|}{ Well 5} & \multicolumn{2}{c|}{ Well 6} \\
\cline { 2 - 14 } & Lag (hr) & $\rho$ & Lag (hr) & $\rho$ & Lag (hr) & $\rho$ & Lag (hr) & $\rho$ & Lag (hr) & $\rho$ & Lag (hr) & $\rho$ \\
\hline No lag & 0 & 0.144 & 0 & 0.053 & 0 & 0.086 & 0 & 0.369 & 0 & -0.109 & & -0.032 \\
\hline$\rho_{\max }$ & 34 & 0.193 & 26 & 0.088 & 80 & -0.119 & 28 & 0.442 & 80 & -0.176 & 80 & .0 .041 \\
\hline
\end{tabular}

All Spearman's correlations are statistically significant for a $95 \%$ confidence level. The correlation coefficient in the first row is between stage and flux with no forward time step. The second row indicates the maximum correlation between stage and flux with incremental 2-hour time steps in flux up to 80 hours of lag time. There are positive and negative statistically significant weak correlations between stage and flux. 


\section{CHAPTER V: DISCUSSION}

\section{Low-Gradient Stream Conceptual Model - Temperature and Flux dynamics}

Little Kickapoo Creek is representative of Midwestern US alluvial streams characterized by its low-gradient, low-energy environment, and a streambed comprised of poorly-consolidated, mobile, glacial sediment (Peterson et al., 2008). On a watershed scale, LKC is defined as a gaining stream with an average baseflow component of $0.1 \mathrm{~m}^{3} / \mathrm{s}$ that can rise to $4 \mathrm{~m}^{3} / \mathrm{s}$ with increases in runoff and tile drainage input (Hayden, 2012; Peterson and Sickbert, 2006).

In LKC, 1-D fluxes fluctuate between positive and negative values indicating groundwater-stream water mixing to a depth of $15 \mathrm{~cm}$ (Fig. 10). Temperature gradients in the fall and spring are a magnitude smaller than the summer and winter representing periods of streambed heat advection from upwelling and downwelling water (Fig. 5; Table 3). Thermal advection is the dominant heat transfer mechanism across the entire streambed profile $(15,45$, $75,120 \mathrm{~cm}$ ) for all six wells (Table 3). In the near-surface streambed $(15 \mathrm{~cm})$, hyporheic fluxes transition from downwelling conditions in the fall, winter, and spring to limited upward flux rates or flux rates approaching zero in the summer (Fig. 10). At streambed depths between $15 \mathrm{~cm}$ to $120 \mathrm{~cm}$, the mean flow direction is positive or upwards (Fig. 9). Propagation of the stream diel temperature signal is limited to the near-subsurface due to the upwelling groundwater having a stronger influence on streambed temperatures from 60 to $150 \mathrm{~cm}$ mitigating the presence of a diel signal. Penetration of a robust diel stream temperature will occur in losing stream conditions by advection and will be less prominent during neutral conductive conditions (flux $=0$ ) or gaining stream conditions (Hatch, 2006).

Overall, hyporheic mixing occurs near the streambed with seasonal variation, while deeper groundwater is upwelling. Supporting this concept, hyporheic zone upwelling aligns with 
the gaining stream results seen in past studies (Bastola and Peterson, 2016; Beach and Peterson, 2013; Peterson and Benning, 2013, Peterson and Sickbert, 2006). Employing the same dataset, Bastola and Peterson (2016) developed a VS2DH numerical temperature model that illustrated advective heat transport in the upward direction. The VS2DH best-fit model rendered average flux rates of $10^{-1}$ to $10^{-2} \mathrm{~m} / \mathrm{d}$ across the $4 \mathrm{~m}$ vertical streambed domain, with lower rates during the wet winter and higher rates in the dry summer due to evapotranspiration (Bastola and Peterson, 2016). The magnitude of flux rates produced in the VS2DH model aligns with that of the rates calculated in this study, and the direction of advective heat transfer is consistent with the groundwater upwelling from 15 to $120 \mathrm{~cm}$ seen in the streambed. Downward flux rates in the top $15 \mathrm{~cm}$ of the streambed are not observed in the VS2DH model, but this model has a coarser spatial resolution of $1 \mathrm{~m}$ compared to the $30 \mathrm{~cm}$ and $60 \mathrm{~cm}$ resolution used in VFLUX. The coarse resolution might average out discrete changes in flux seen at $15 \mathrm{~cm}$ due to spatial calculation frequency being too small the VS2DH model. Bastola and Peterson (2016) report the influence of the stream on the temperature to a depth of $30 \mathrm{~cm}$ suggesting the near-surface hyporheic zone is more dynamic than the deeper substrate. This study exhibits a stronger capability to see small spatial changes in fluxes in the LKC hyporheic zone. Thermal envelopes also show a stream influence in the top $50 \mathrm{~cm}$ depth of the streambed (Bastola and Peterson, 2016) similar to the groundwater transition zone seen in this study. Overall, LKC Temperature models display upward groundwater advection dominating the LKC streambed, and LKC solute models point to hyporheic mixing conditions in the near-subsurface with deeper groundwater upwelling.

Temperature is a non-reactive conservative tracer, and the transport mechanisms will vary from that of conservative solutes. Thermal energy transfer in the streambed is governed by 
conduction and advection and will change naturally in response to the upper-boundary condition, while conservative solutes are explained by diffusion and advection. Thermal energy does not change into another form of energy, but heat is lost in the streambed due to the high heat capacity of the streambed matrix. The use of heat as a tracer is constrained to a shallower depth of the hyporheic zone when compared to solute studies due to its non-conservative nature. The spatial scale of heat tracing studies is dependent on the rate of hyporheic movement in through the solid streambed matrix. In streams with lower flux rates such as LKC, the spatial scale will be smaller than studies with higher flux rates. LKC solute models reported similar depths of surface water-groundwater transition zones and percent stream water composition at depth compared to the thermal models. A LKC chloride mixing model found stream water composition of $50 \%$ at 90 to $130 \mathrm{~cm}$ depth in the streambed with a decline in stream water percent in the summer season (Buyck, 2005). Hayden (2012), concluded that the transition zone between the hyporheic zone and groundwater is between 90 and $150 \mathrm{~cm}$ depth in the fall and winter and decreases between 60 to $90 \mathrm{~cm}$ in the summer. Both chemical mixing models report decreased surface water composition at streambed depth during the summer months explaining the limited amount of hyporheic mixing occurring in the summer (Fig. 10). During the summer, groundwater upwelling dominates the hyporheic zone and hyporheic mixing is limited. Bastola and Peterson's (2016) best-fit models approximated similar surface water extinction depths to Hayden (2012) and Buyck (2005) at approximately $1 \mathrm{~m}$ in the summer and winter and $3 \mathrm{~m}$ in the spring. Extinction depths, defined by the terminus of a diurnal signal in the shallow substrate, do not accurately represent hyporheic flow depths. Thermal models are spatially limited due to the non-conservative nature that constrains the depth that hyporheic water is identified within the streambed. Fall and spring temperature profiles are homogenous with depth. In the fall and 
spring the stream thermal signal will propagate into the streambed at a greater depth compared to the summer and winter with a larger temperature gradient across the streambed profile. Significant differences in streambed and stream temperatures will mute stream temperature signals at a shallower depth due to competing groundwater temperature. The advantage of the VFLUX model results is the fine temporal resolution and discrete flux calculations with depth that give rise to transient mixing conditions in the near-surface streambed with deeper groundwater upwelling.

\section{Stage as a Control of 1-D Vertical Flux}

Along the LKC stretch, stage exhibits weak statistically significant correlation to fluxes at the $15 \mathrm{~cm}$ midpoint within the near-surface hyporheic zone. The bivariate relationship is both positive and negative. Stage and discharge are expected to elevate the pressure gradient along the streambed increasing the magnitude of flux in the downward direction by vertical compression (negative correlation). Stage is not the only variable contributing to flux, and other variables such as stream velocity need to be accounted for in the fluid potential calculation (Sickbert and Peterson, 2014). Sickbert and Peterson (2014) found that total head in the shallow subsurface of LKC increased less than the corresponding stage increase. The lower head values reflect the effect of velocity increases associated with the high stage. Bernoulli's Equation explains that an increase in fluid velocity will result in a pressure reduction. The resulting decrease in pressure from an increased velocity creates a fluid-lift force that lessens the influence of the head exerted by stage on the hydraulic head in the hyporheic zone and resulting fluxes. As stage increases, the stream velocity increases, reducing the vertical head gradient due to the reduced pressure. (Sickbert and Peterson, 2014). A rise in stage not only raises the total hydraulic head in the streambed, but the resulting velocity increase by a rise in stage will alleviate and reduce the total 
vertical pressure gradient due to the fluid lift force. If the pressure reduction due to an increase in velocity is large enough, it could hypothetically reverse the pressure gradient creating a negative suction head in the stream. This might explain the weak positive correlations seen between stage and flux at the $15 \mathrm{~cm}$ midpoint depth in table 4 . Again, a positive correlation between stage and flux implies that as stream stage rises, hyporheic fluxes increase in the upward direction (gaining stream condition). Stream velocity should be accounted for, and it is invalid to assume that stage alone will control the magnitude and direction of hyporheic flux. Stage does not have a strong correlation to vertical 1-D flux in LKC with Bernoulli's lift force being a likely candidate contributing to the control of hyporheic flux.

The weak correlation between stage and flux in the near-surface streambed $(15 \mathrm{~cm})$ is a possible reflection of the stage magnitude variance being too small to influence or reverse the regional pressure gradient serving as a minor control on hyporheic flow. Hayden (2012) found that stage closely mirrors the groundwater elevation, but the elevation of groundwater near the stream is higher than the stream. The lateral gradient towards the stream is the highest in the fall and summer inducing strong groundwater upwelling in the summer months. The hyporheic zone has a limited capacity to take in water, which is controlled by potential and kinetic energy gradients. There is a sharp contrast in the hydraulic conductivity between the stream and the streambed limiting flux into the streambed without a pressure gradient. Studies looking at controls on hyporheic exchange have focused on microfeatures in the streambed that have longitudinal pressure gradients that induce flow into the streambed bedforms. This phenomenon is seen in streambeds with wave-like bedforms, bars, riffles, and pools. As stage rises, bedforms along the stream bed will allow a flux initially due to a longitudinal differential pressure across the bedform, but the fluxes decrease as a longitudinal pressure gradient is eliminated by a rise in 
stage. Storey et al. (2003) found that high stage did not correlate to higher hyporheic exchange in bedforms and saw increases in exchange when stage was low, and the water surface followed the streambed topography.

Visual evaluation of the data (Fig. 10) suggests a connection between stage and flux at the $15 \mathrm{~cm}$ midpoint streambed depth, with flux rates close to zero or positive (upwelling) when stage is lowest in the summer and opposite for the fall, spring, and winter. It is likely that multiple variables are governing hyporheic exchange. The following hydrodynamic and geomorphic variables are potential predictors of hyporheic exchange rates: streambed morphology, streambed conductivity, channel slope, stream sinuosity, horizontal stream velocity, hydraulic and vertical gradient in the microscopic stream-streambed and watershed scale, and stream stage or discharge that control the hyporheic flux (Harvey and Bencala, 1993; Hester and Doyle, 2008; Hill et al., 1998; Kasahara and Wondzell, 2003; Ward et al., 2012; Schmadel et al., 2017). The LKC study site was selected due to the stream segments low sinuosity and lack of geomorphic features such as riffles, bars, steps, and pools. Harvey and Bencala (1993) found morphologic features induce hyporheic exchange in mountainous settings from alternating pressure variations over undulating forms in the streambed. Morphologic features and strong curvatures in a longitudinal stream profile should have a minor control on hyporheic exchange at the site LKC location since there is a lack of these features at the study site. Low-gradient meandering streams can have active hyporheic zones within meander lobe necks (Peterson and Sickbert, 2009). Peterson and Sickbert (2006) found that the hydraulic gradient across a meander neck lobe was higher than the hydraulic gradient across the longitudinal stream path inducing advective flow across the meander neck. Ward et al. (2012) found that hydraulic gradients parallel and perpendicular to the stream bank are not sufficient 
predictors of hyporheic exchange flux alone in a high-gradient environment. The extent of the hyporheic zone does vary with flow rate, but there are no absolute trends (Ward et al., 2012). Ward et al. (2012) saw the smallest and largest degree of hyporheic area with low, intermediate, and high flow rates. Several studies show that a wide range in stream discharge, a proxy for stage, has minor variation or influence in hyporheic exchange flow paths, flux, or residence time (Schmadel et al., 2017; Ward et al., 2017). 


\section{CHAPTER VI: CONCLUSION}

LKC is a low-gradient stream with an actively mixing hyporheic zone in the top $15 \mathrm{~cm}$ during the winter, spring, and fall with deeper upwelling groundwater. Above $15 \mathrm{~cm}$ the LKC hyporheic zone is actively mixing perennially with a negligible exchange in the summer as flux rates approach zero. Across the 14-month time series fluxes have the highest magnitude in winter and spring. The lowest flux rates occur in the summer when stage is low compared to other seasons. Processes of denitrification are pertinent in central Illinois with a significant amount of fertilized agricultural land. The LKC hyporheic zone denitrification potential is significant in the spring, winter, and fall when hyporheic mixing is present, but low in the summer when hyporheic exchange is low. This study provides a stronger understanding of seasonal hyporheic exchange and will help nutrient and ecological studies understand flux dynamics in low-gradient streams.

Stage is a weak variable contributing to fluxes, but the $15 \mathrm{~cm}$ fluxes converge to zero when stage is lowest in the summer. A multivariate regression analysis is advised to better understand the variables that are controlling the magnitude and direction of flux. Discovering the relationship between the regional gradient and flux is crucial to understanding the mechanisms of hyporheic exchange. There were no nearby wells with recorded head values to obtain a regional gradient during the study period.

The results of this study highlight hyporheic flux as a multivariate function that cannot be determined solely by stage. Hyporheic flux in the near-surface streambed $(15 \mathrm{~cm})$ is not a function of purely hydrostatic processes and the hydrodynamic and geomorphic controls should be further investigated. There is a lack of studies that investigate the variables controlling hyporheic exchange flux and residence time (Harvey and Bencala, 1993; Hester and Doyle, 
2008; Hill et al., 1998; Kasahara and Wondzell, 2003; Ward et al., 2012; Ward et al., 2016). While a strong understanding of the effects of streambed geomorphology and topography on hyporheic exchange exists (Harvey and Bencala, 1993; Hester and Doyle, 2008; Hill et al., 1998; Kasahara and Wondzell, 2013), there is minimal understanding of other hydrodynamic and hydrostatic forcing mechanisms such as stage, discharge, and stream velocity. The controls on streambed advection and dispersion have been analyzed in alpine high-gradient settings (Schmadel et al., 2017; Ward et al., 2012, Ward et al., 2017; Ward et al., 2016); however, little data has been reported in low-gradient stream environments (Sickbert and Peterson, 2014; Storey et al., 2003). In the studies that have been performed, both, high and low environments show a lack of control of stage or discharge on flux rates in the hyporheic zone. Storey et al. (2003) found a negative correlation between stage and hyporheic exchange in streambed wave-like forms in a low-gradient environment. Velocity is contributing to bank hyporheic exchange in low-gradient settings (Sickbert and Peterson, 2014). Geomorphic controls such as bedforms and other hydrodynamic controls such as lateral gradient should be focused on in low-gradient settings for future studies. It is evident that stage alone is not playing a strong role in hyporheic exchange in high and low-gradient streams. It is important to understand the underlying variables that govern hyporheic exchange in a variety of catchments to facilitate the development of ecological models, chemical solute models, and nutrient dynamics that extend into the hyporheic zone. 


\section{REFERENCES}

Ackerman, J. R., Peterson, E. W., Van der Hoven, S., and Perry, W. L., 2015, Quantifying nutrient removal from groundwater seepage out of constructed wetlands receiving treated wastewater effluent: Environmental Earth Sciences, v. 74, no. 2, p. 1633-1645.

Allander, K. K., 2003, Trout Creek-Evaluating ground-water and surface water exchange along an alpine stream, Lake Tahoe, California: Heat as a Tool for Studying the Movement of Ground Water Near Streams, ed. DA Stonestrom and J. Constantz, p. 35-45.

Anderson, M. P., 2005, Heat as a ground water tracer: Ground Water, v. 43, no. 6, p. 951-968.

Bastola, H., and Peterson, E. W., 2016, Heat tracing to examine seasonal groundwater flow beneath a low-gradient stream in rural central Illinois, USA: Hydrogeology Journal, v. 24, no. 1, p. 181-194.

Basu, A., 2007, Quantifying N cycling between groundwater and surface water using numerical modeling and mass flux calculations. Master's thesis, Department of Geography-Geology Illinois State University.

Baxter, C. V., and Hauer, F. R., 2000, Geomorphology, hyporheic exchange, and selection of spawning habitat by bull trout (Salvelinus confluentus): Canadian Journal of Fisheries and Aquatic Sciences, v. 57, no. 7, p. 1470-1481.

Beach, V., and Peterson, E. W., 2013, Variation of hyporheic temperature profiles in a low gradient third-order agricultural stream-a statistical approach: Open Journal of Modern Hydrology, v. 3, no. 02, p. 55.

Bencala, K. E., 2000, Hyporheic zone hydrological processes: Hydrological Processes, v. 14, no. 15, p. $2797-2798$.

Boulton, A. J., Findlay, S., Marmonier, P., Stanley, E. H., and Valett, H. M., 1998, The functional significance of the hyporheic zone in streams and rivers: Annual Review of Ecology and Systematics, p. 59-81.

Briggs, M. A., Lautz, L. K., McKenzie, J. M., Gordon, R. P., and Hare, D. K., 2012, Using high-resolution distributed temperature sensing to quantify spatial and temporal variability in vertical hyporheic flux: Water Resour. Res., v. 48, no. 2, p. W02527.

Buyck, M. S., 2005, Tracking nitrate loss and modeling flow through the hyporheic zone of a low gradient stream through the use of conservative tracers. Master's thesis, Department of Geography-Geology Illinois State University.

Cardenas, M. B., Wilson, J. L., and Zlotnik, V. A., 2004, Impact of heterogeneity, bed forms, and stream curvature on subchannel hyporheic exchange: Water Resources Research, v. 40, no. 8 . 
Conant Jr., B., 2004, Delineating and quantifying ground water discharge zones using streambed temperatures: Ground Water, v. 42, no. 2, p. 243-257.

Constantz, J., 2008, Heat as a tracer to determine streambed water exchanges: Water Resources Research, v. 44, no. 4.

Cozzetto, K., McKnight, D., Nylen, T., and Fountain, A., 2006, Experimental investigations into processes controlling stream and hyporheic temperatures, Fryxell Basin, Antarctica: Advances in Water Resources, v. 29, no. 2, p. 130-153.

Deming, D, 2002, Introduction to hydrogeology, McGraw-Hill College.

Findlay, S., 1995, Importance of surface-subsurface exchange in stream ecosystems: The hyporheic zone: Limnology and oceanography, v. 40, no. 1, p. 159-164.

Freeze, R. A., 1985, Historical correspondence between CV Theis and CI Lubin: Eos Trans, AGU, v. 66, p.441-448.

Gordon, R. P., Lautz, L. K., Briggs, M. A., and McKenzie, J. M., 2012, Automated calculation of vertical pore-water flux from field temperature time series using the VFLUX method and computer program: Journal of Hydrology, v. 420, p. 142-158.

Goto, S., Yamano, M., and Kinoshita, M., 2005, Thermal response of sediment with vertical fluid flow to periodic temperature variation at the surface: Journal of Geophysical Research: Solid Earth, v. 110, no. B1.

Hannah, D. M., Malcolm, I. A., Soulsby, C., and Youngson, A. F., 2004, Heat exchanges and temperatures within a salmon spawning stream in the Cairngorms, Scotland: seasonal and sub-seasonal dynamics: River Research and Applications, v. 20, no. 6, p. 635-652.

Hansel, A. K., and Johnson, W. H., 1996, Wedron and Mason Groups: Lithostratigraphic reclassification of deposits of the Wisconsin Episode, Lake Michigan lobe area: Bulletin no. 104.

Hartz, M., Malone, D., and Nelson, R., 2016, Three-Dimensional Geologic Model of Glacial Outwash in Mclean County, Illinois, Based on Seismic Refraction Studies: Geosciences, v. 6 , no. 1, p. 9 .

Harvey, J. W., and Bencala, K. E., 1993, The effect of streambed topography on surfacesubsurface water exchange in mountain catchments: Water Resources Research, v. 29, no. 1, p. 89-98.

Harvey, J.E. and B.J. Wagner, 2000. Quantifying Hydrologic Interactions Between Streams and Their Subsurface Hyporheic Zones. In: Streams and Groundwaters, J.A. Jones and P.J. Mulholland (Editors). Academic Press, New York, pp. 3-44. 
Hatch, C. E., Fisher, A. T., Revenaugh, J. S., Constantz, J., and Ruehl, C., 2006, Quantifying surface water-groundwater interactions using time series analysis of streambed thermal records: Method development: Water Resources Research, v. 42, no. W10410.

Hatch, C. E., Fisher, A. T., Ruehl, C. R., and Stemler, G., 2010, Spatial and temporal variations in streambed hydraulic conductivity quantified with time-series thermal methods: Journal of Hydrology, v. 389, no. 3, p. 276-288.

Hayden, K. M., 2012, Seasonal and Diurnal Variation of Nitrate Concentrations Within the Hyporheic Zone of a Low-gradient, Third-order Stream in Central Illinois, Master's thesis, Department of Geography-Geology, Illinois State University.

Hester, E. T., and Doyle, M. W., 2008, In-stream geomorphic structures as drivers of hyporheic exchange: Water Resources Research, v. 44, no. 3.

Hill, A. R., Labadia, C. F., and Sanmugadas, K., 1998, Hyporheic zone hydrology and nitrogen dynamics in relation to the streambed topography of a N-rich stream: Biogeochemistry, v. 42 , no. 3 , p. $285-310$.

Hinkle, S. R., Duff, J. H., Triska, F. J., Laenen, A., Gates, E. B., Bencala, K. E., Wentz, D. A., and Silva, S. R., 2001, Linking hyporheic flow and nitrogen cycling near the Willamette River - a large river in Oregon, USA: Journal of hydrology, v. 244, no. 3-4, p. 157-180.

Huettel, M., Røy, H., Precht, E., and Ehrenhauss, S., 2003, Hydrodynamical impact on biogeochemical processes in aquatic sediments, The Interactions between Sediments and Water, Springer, p. 231-236.

Hynes, H. B. N., 1983, Groundwater and Stream Ecology: Hydrobiologia, v. 100, no. 1, p. 93 99.

Irvine, D. J., Lautz, L. K., Briggs, M. A., Gordon, R. P., and McKenzie, J. M., 2015, Experimental evaluation of the applicability of phase, amplitude, and combined methods to determine water flux and thermal diffusivity from temperature time series using VFLUX 2: Journal of Hydrology, v. 531, p. 728-737.

Jensen, J. K., and Engesgaard, P., 2011, Nonuniform groundwater discharge across a streambed: Heat as a tracer: Vadose Zone Journal, v. 10, no. 1, p. 98-109.

Kasahara, T., and Wondzell, S. M., 2003, Geomorphic controls on hyporheic exchange flow in mountain streams: Water Resources Research, v. 39, no. 1.

Keery, J., Binley, A., Crook, N., and Smith, J. W. N., 2007, Temporal and spatial variability of groundwater-surface water fluxes: Development and application of an analytical method using temperature time series: Journal of Hydrology, v. 336, no. 1-2, p. 1-16.

Kisfalusi, Z. D., 2016, The effects of tile-drain input on a low-gradient agricultural stream in central Illinois: Using a thermal end member mixing model and a statistical analysis approach, Master's thesis, Department of Geology-Geography, Illinois State University. 
Lapham, W. W., 1989, Use of temperature profiles beneath streams to determine rates of vertical ground-water flow and vertical hydraulic conductivity: Dept. of the Interior, US Geological Survey; USGPO; Books and Open-File Reports Section, US Geological Survey [distributor].

Luce, C. H., Tonina, D., Gariglio, F., and Applebee, R., 2013, Solutions for the diurnally forced advection-diffusion equation to estimate bulk fluid velocity and diffusivity in streambeds from temperature time series: Water Resources Research, v. 49, no. 1, p. 488-506.

McCallum, A. M., Andersen, M. S., Rau, G. C., and Acworth, R. I., 2012, A 1-D analytical method for estimating surface water-groundwater interactions and effective thermal diffusivity using temperature time series: Water Resources Research, v. 48, no. 11.

Mulholland, P. J., and D. L. DeAngelis (2000), Surface-Subsurface exchange and nutrient spiraling, in Streams and Ground Waters, edited by J. B. Jones, and P. J. Mulholland, pp. 149-166, Elsevier, New York.

Oware, E. K., 2010, The Impact of Storms on Thermal Transport Within the Hyporheic Zone of a Low Gradient Third-Order Sand and Gravel Bedded Stream, Master's thesis, Department of Geography-Geology, Illinois State University.

Peterson, E. W., and Benning, C., 2013, Factors influencing nitrate within a low-gradient agricultural stream: Environmental earth sciences, v. 68, no. 5, p. 1233-1245.

Peterson, E. W., and Sickbert, T. B., 2006, Stream water bypass through a meander neck, laterally extending the hyporheic zone: Hydrogeology Journal, v. 14, no. 8, p. 14431451.

Peterson, E. W., Sickbert, T. B., and Moore, S. L., 2008, High frequency stream bed mobility of a low-gradient agricultural stream with implications on the hyporheic zone: Hydrological processes, v. 22, no. 21, p. 4239-4248.

Riggs, M. H., and Abert, C. C., 1997, Cumulative sand and gravel thickness in McLean County, Illinois: Open File Series 1997-01f.

Schmadel, N. M., Ward, A. S., and Wondzell, S. M., 2017, Hydrologic controls on hyporheic exchange in a headwater mountain stream: Water Resources Research, v. 53, no. 7, p. 6260-6278.

Sickbert, T., and Peterson, E. W., 2014, The Effects of Surface Water Velocity on Hyporheic Interchange: Journal of Water Resource and Protection, v. 6, no. 4, p. 327.

Silliman, S. E., and Booth, D. F., 1993, Analysis of time-series measurements of sediment temperature for identification of gaining vs. losing portions of Juday Creek, Indiana: Journal of Hydrology, v. 146, p. 131-148. 
Stallman, R. W., 1965, Steady one-dimensional fluid flow in a semi-infinite porous medium with sinusoidal surface temperature: Journal of geophysical Research, v. 70, no. 12, p. 2821-2827.

Stanford, J. A., 1998, Rivers in the landscape: introduction to the special issue on riparian and groundwater ecology: Freshwater Biology, v. 40, no. 3, p. 402-406.

Storey, R. G., Howard, K. W. F., and Williams, D. D., 2003, Factors controlling riffle-scale hyporheic exchange flows and their seasonal changes in a gaining stream: A threedimensional groundwater flow model: Water Resources Research, v. 39, no. 2.

Suzuki, S., 1960, Percolation measurements based on heat flow through soil with special reference to paddy fields: Journal of Geophysical Research, v. 65, no. 9, p. 2883-2885.

Swanson, T. E., and Cardenas, M. B., 2011, Ex-Stream: A MATLAB program for calculating fluid flux through sediment-water interfaces based on steady and transient temperature profiles: Computers \& Geosciences, v. 37, p. 1664-1669.

Team, R. C., 2014, R: A language and environment for statistical computing (Version 3.0. 2): R Foundation for Statistical Computing, Vienna, Austria.

Theis, C. V., 1935, The relation between the lowering of the Piezometric surface and the rate and duration of discharge of a well using ground-water storage: Eos, Transactions American Geophysical Union, v. 16, no. 2, p. 519-524.

Van der Hoven, S. J., Fromm, N. J., and Peterson, E. W., 2008, Quantifying nitrogen cycling beneath a meander of a low gradient, $\mathrm{N}$-impacted, agricultural stream using tracers and numerical modelling: Hydrological Processes, v. 22, no. 8, p. 1206-1215.

Vervier, P., Gibert, J., Marmonier, P., and Dole-Olivier, M.-J., 1992, A perspective on the permeability of the surface freshwater-groundwater ecotone: Journal of the North American Benthological Society, p. 93-102.

Ward, A. S., Fitzgerald, M., Gooseff, M. N., Voltz, T. J., Binley, A. M., and Singha, K., 2012, Hydrologic and geomorphic controls on hyporheic exchange during base flow recession in a headwater mountain stream: Water Resources Research, v. 48, no. 4.

Ward, A. S., Schmadel, N. M., Wondzell, S. M., Gooseff, M. N., and Singha, K., 2017, Dynamic hyporheic and riparian flow path geometry through base flow recession in two headwater mountain stream corridors: Water Resources Research, v. 53, no. 5, p. 3988-4003.

Ward, A. S., Schmadel, N. M., Wondzell, S. M., Harman, C., Gooseff, M. N., and Singha, K., 2016, Hydrogeomorphic controls on hyporheic and riparian transport in two headwater mountain streams during base flow recession: Water Resources Research, v. 52, no. 2, p. 1479-1497.

Willman, H. B., and Frye, J. C., 1970, Pleistocene stratigraphy of Illinois: Bulletin no. 094. 
Winter, T. C., and Geological Survey (U.S.), 1998, Ground water and surface water: a single resource, Denver, CO, U.S. Dept. of the Interior, U.S. Geological Survey, U S Geological Survey circular, v. 1139, vii, 79 p. p.:

Woessner, W. W., 2000, Stream and fluvial plain ground water interactions: rescaling hydrogeologic thought: Ground Water, v. 38, no. 3, p. 423-429.

Wondzell, S. M., 2011, The role of the hyporheic zone across stream networks: Hydrological Processes, v. 25, no. 22, p. 3525-3532.

Wondzell, S. M., and Gooseff, M. N., 2013, 9.13 Geomorphic controls on hyporheic exchange across scales: Watersheds to particles: Treatise on Geomorphology, p. 203-218.

Young, P. C., Pedregal, D. J., and Tych, W., 1999, Dynamic harmonic regression: Journal of forecasting, v. 18, no. 6, p. 369-394.

Young, P. C., Taylor, C. J., Tych, W., Pegregal, D. J., and McKenna, P. G., 2010, The Captain Toolbox. Centre for Research on Environmental Systems and Statistics, Lancaster University, UK. Internet.

Zarnetske, J. P., Haggerty, R., Wondzell, S. M., and Baker, M. A., 2011, Dynamics of nitrate production and removal as a function of residence time in the hyporheic zone: Journal of Geophysical Research: Biogeosciences, v. 116, no. G1. 
APPENDIX: TEMPERATURE AND FLUX AT WELLS 2-6

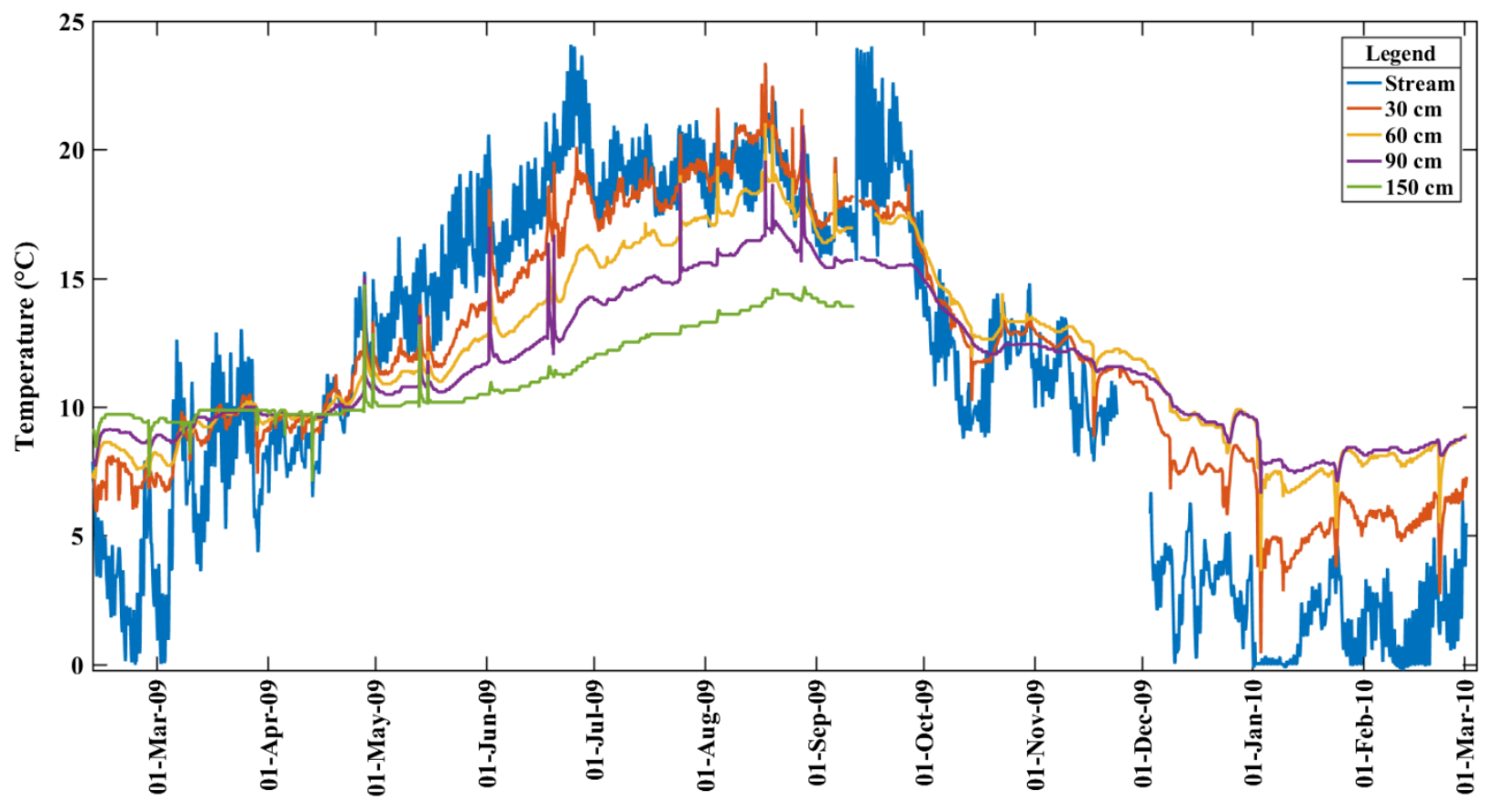

Fig. A-12 Raw stream and streambed temperature time series measured in well 2. The stream temperature included in the graph was measured in well 1. 


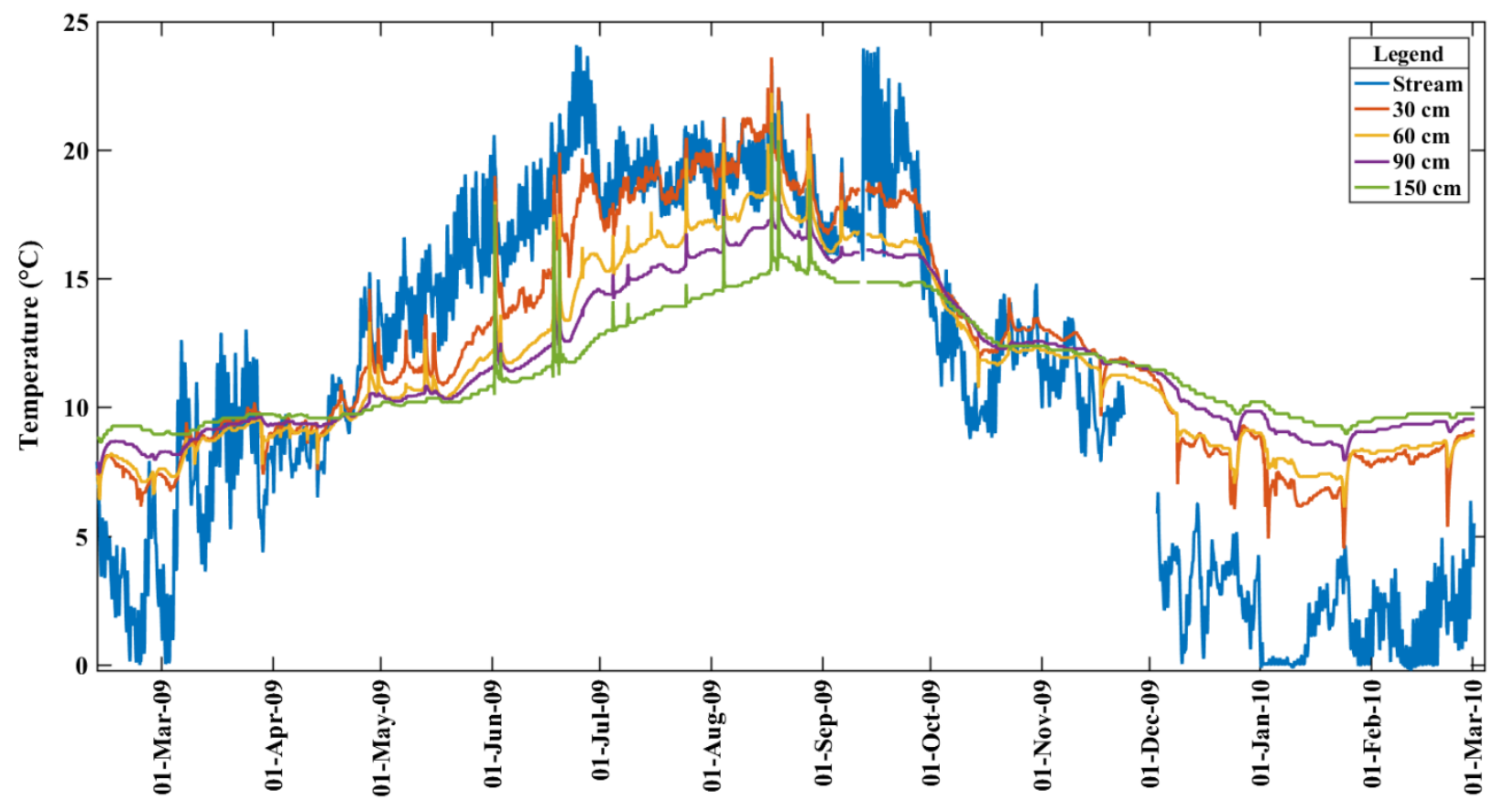

Fig. A-13 Raw stream and streambed temperature time series measured in well 3. The stream temperature included in the graph was measured in well 1. 


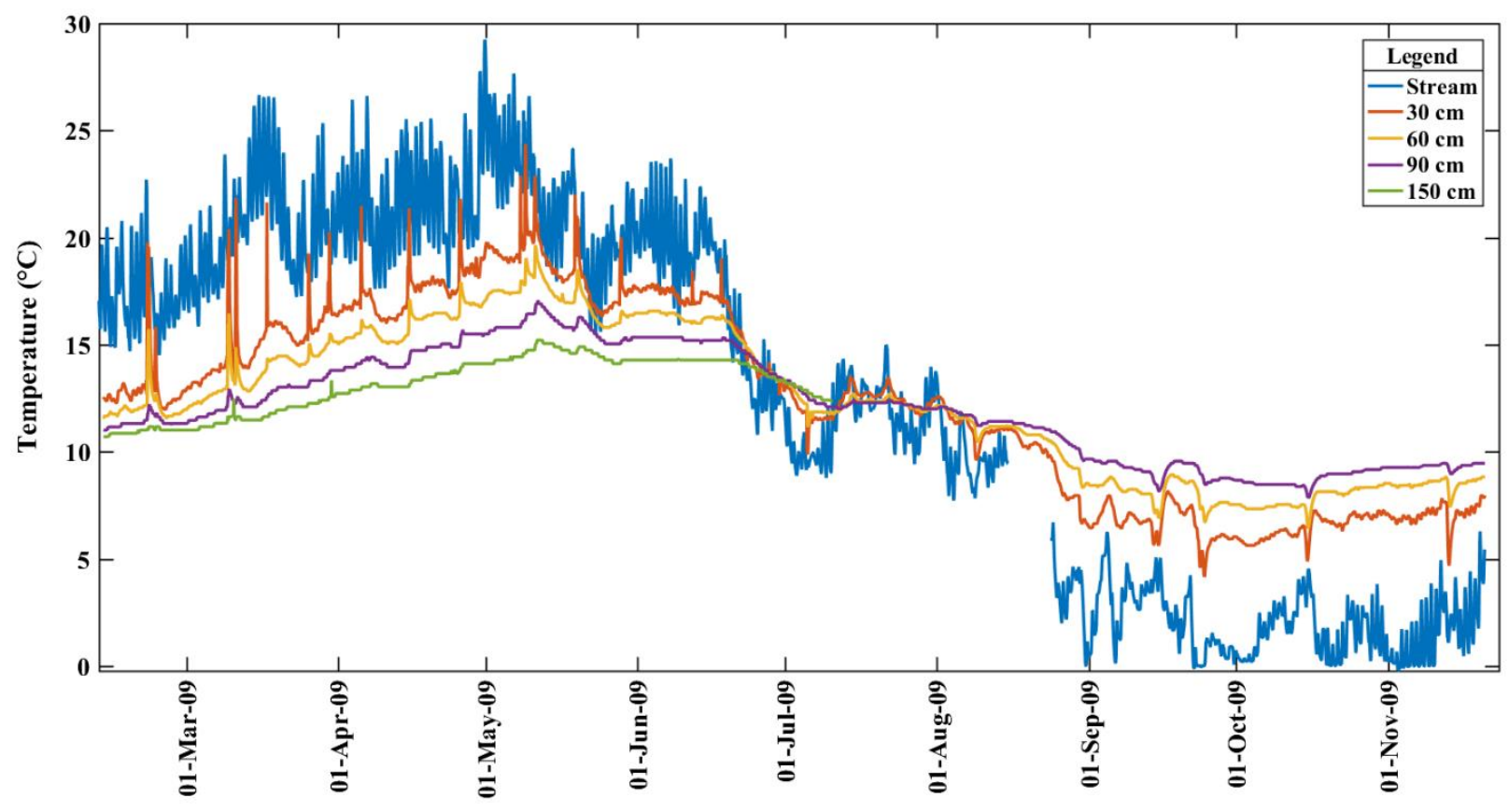

Fig. A-14 Raw stream and streambed temperature time series measured in well 4 . The stream temperature included in the graph was measured in well 6. 


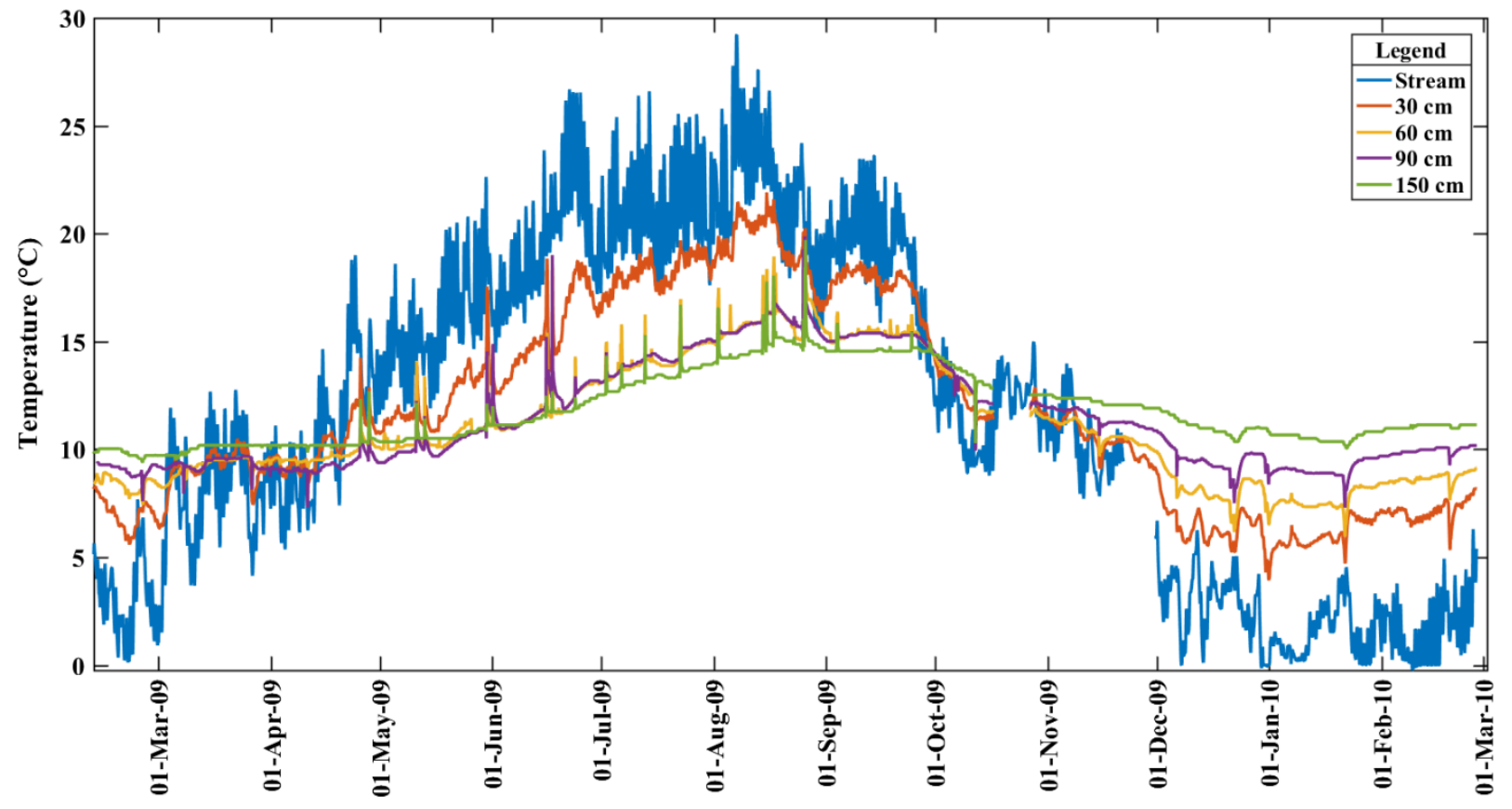

Fig. A-15 Raw stream and streambed temperature time series measured in well 5. The stream temperature included in the graph was measured in well 6 . 


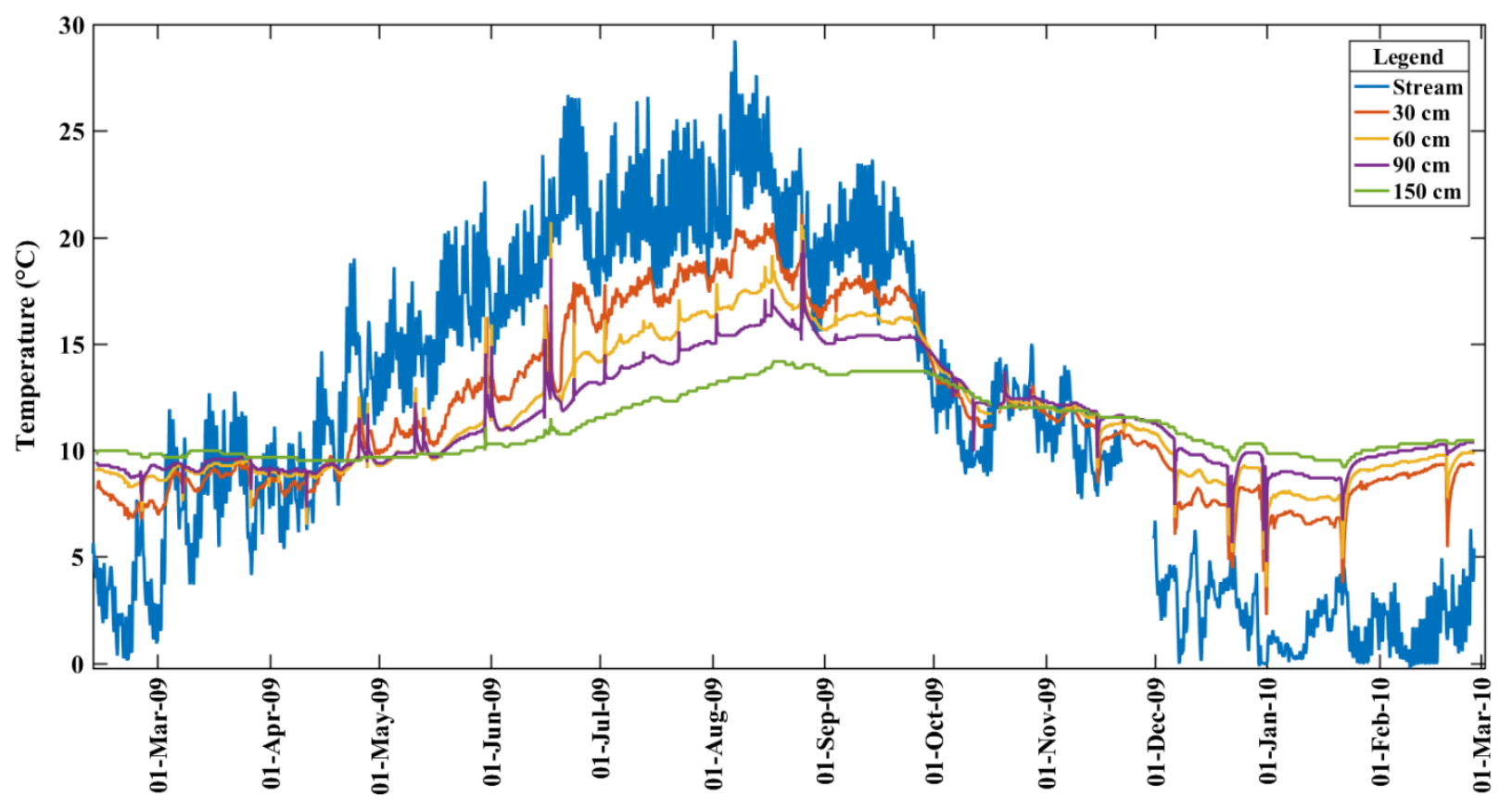

Fig. A-16 Raw stream and streambed temperature time series measured in well 6 . 


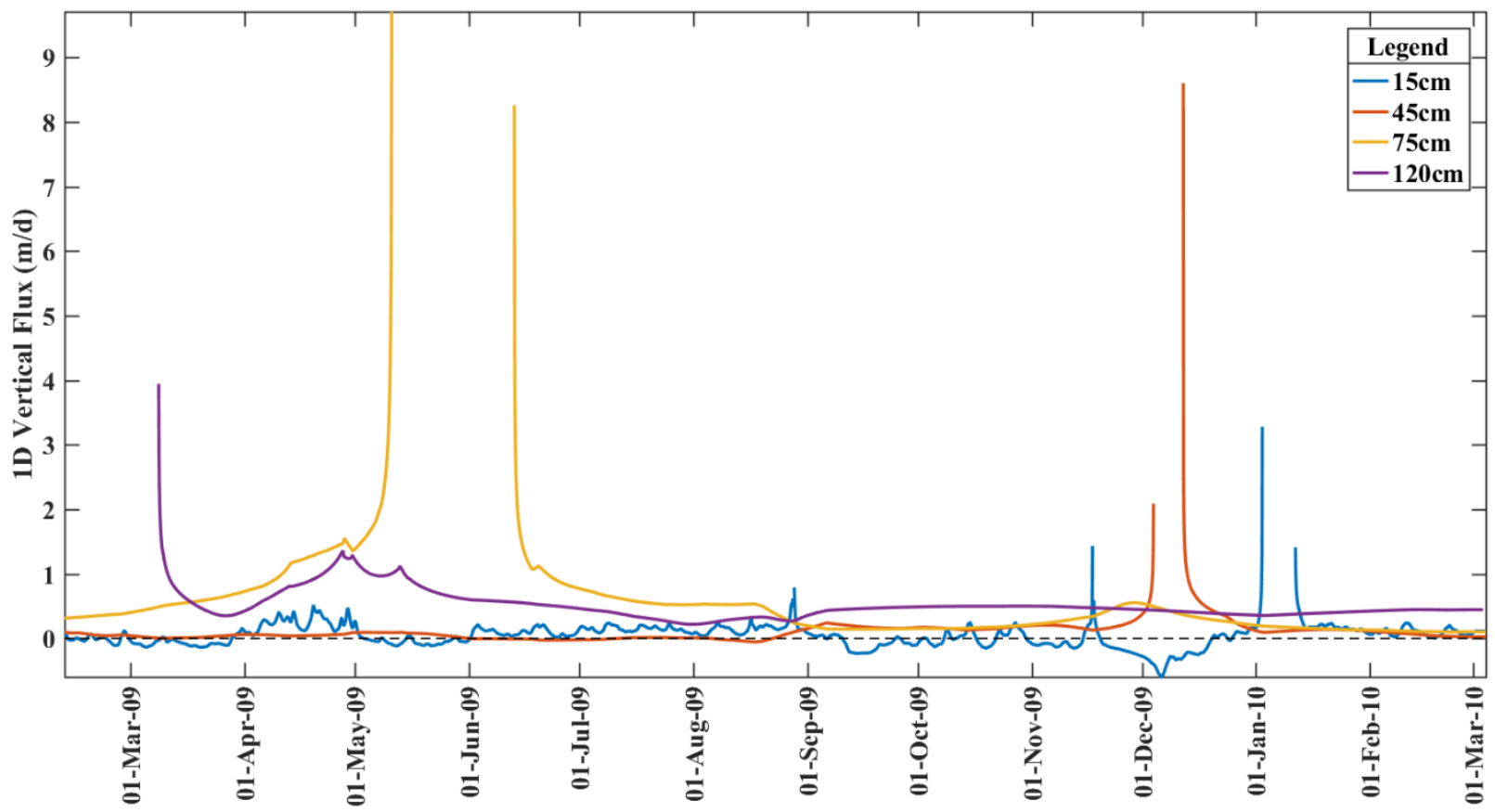

Fig. A-17 1-D vertical flux time series for midpoint depths of 15, 45, 75, and $120 \mathrm{~cm}$ for well 2. Vertical 1-D Fluxes are calculated at the midpoint between temperature sensors. 


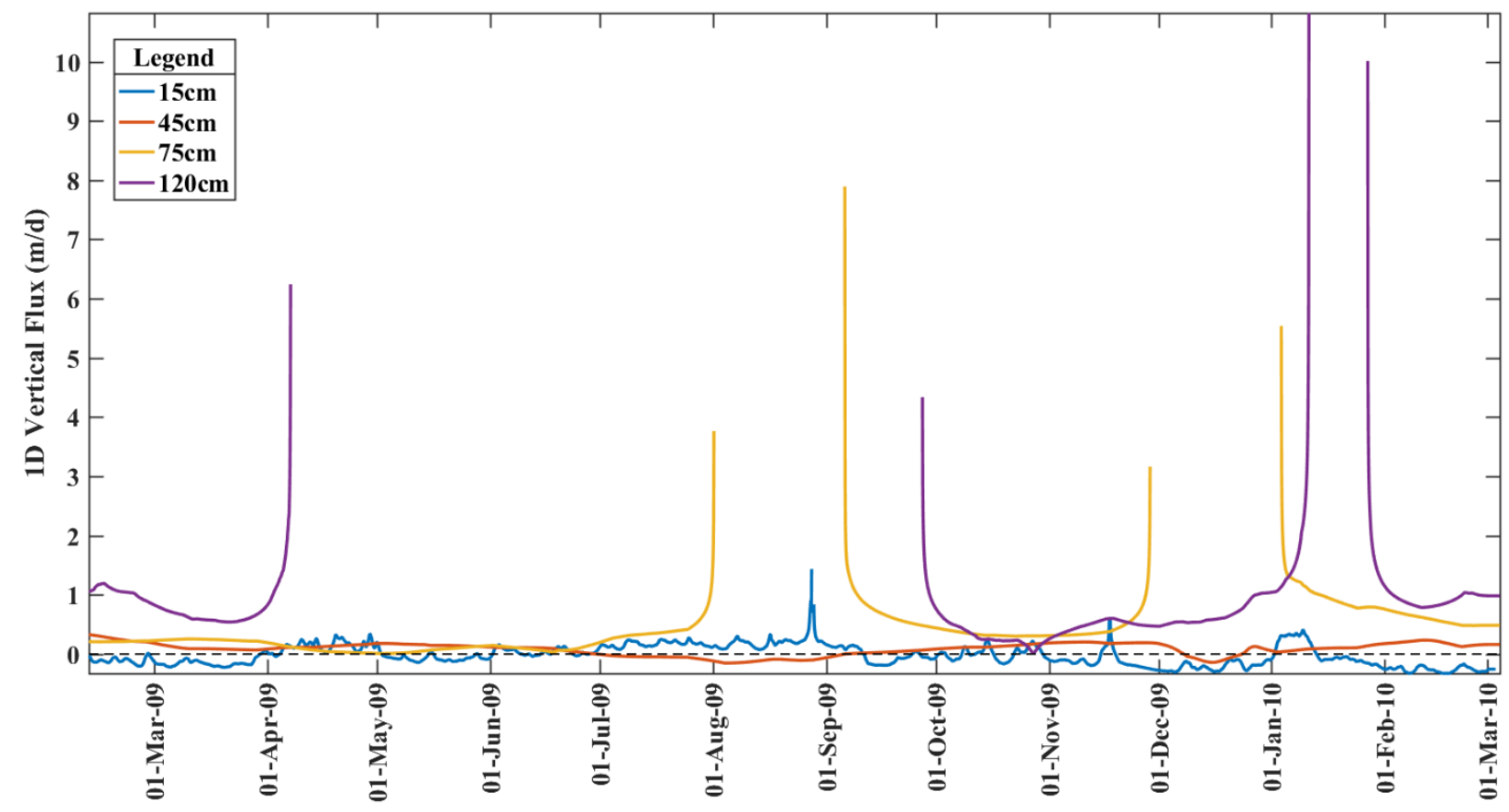

Fig. A-18 1-D vertical flux time series for midpoint depths of 15, 45, 75, and $120 \mathrm{~cm}$ for well 3. Vertical 1-D Fluxes are calculated at the midpoint between temperature sensors. 


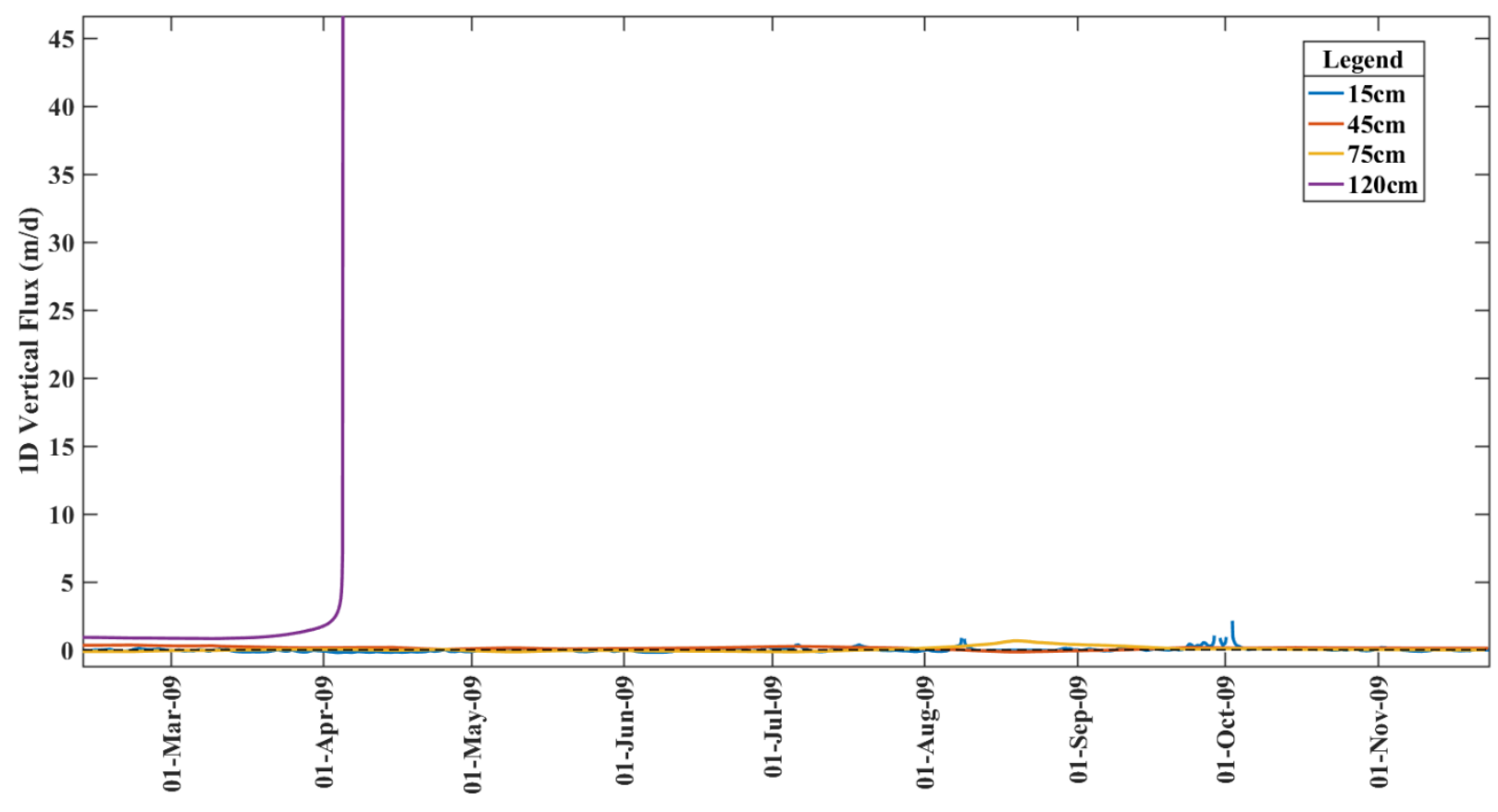

Fig. A-19 1-D vertical flux time series for midpoint depths of 15, 45, 75, and $120 \mathrm{~cm}$ for well 4 . Vertical 1-D Fluxes are calculated at the midpoint between temperature sensors. 


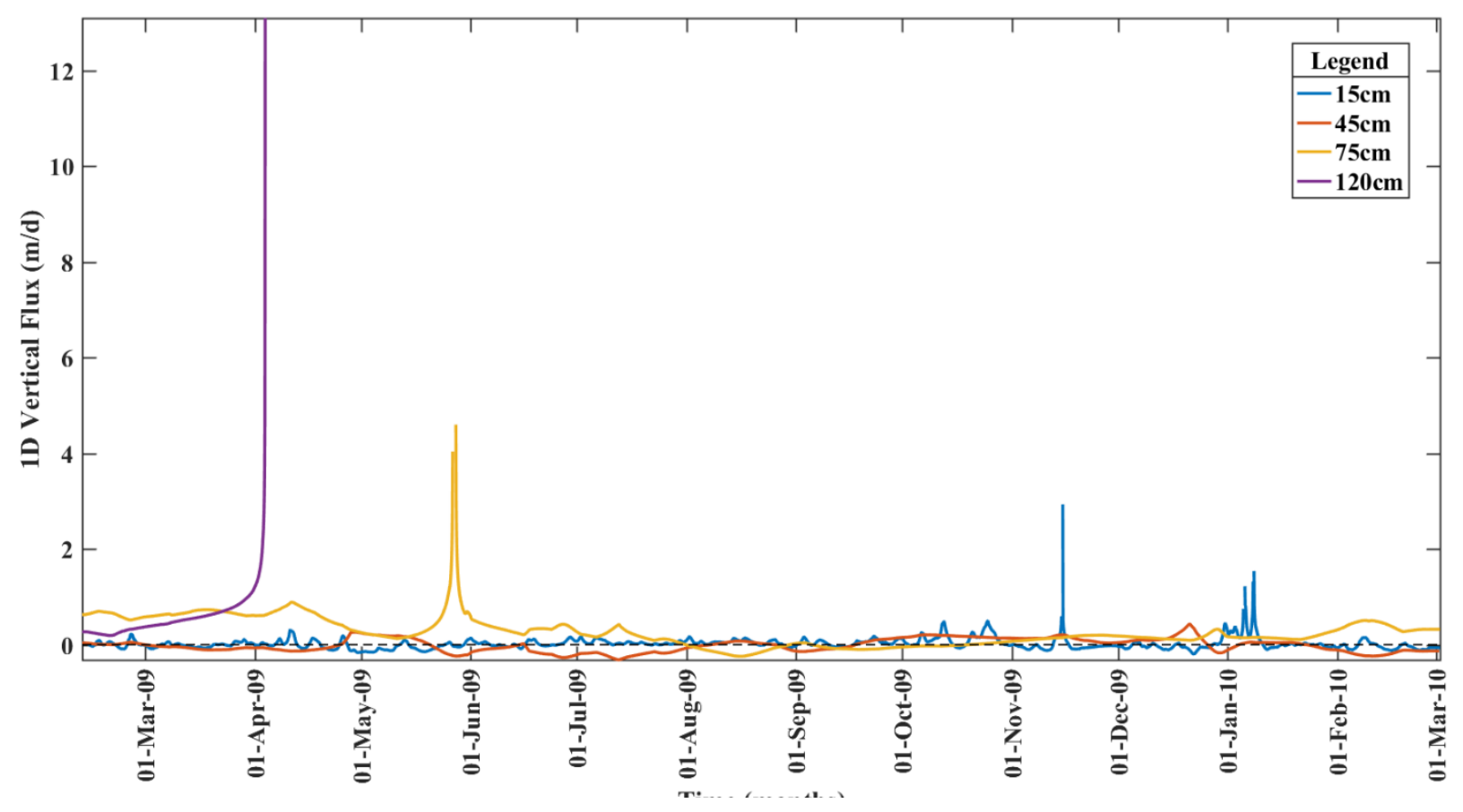

Fig. A-20 1-D vertical flux time series for midpoint depths of 15, 45, 75, and $120 \mathrm{~cm}$ for well 5. Vertical 1-D Fluxes are calculated at the midpoint between temperature sensors. 


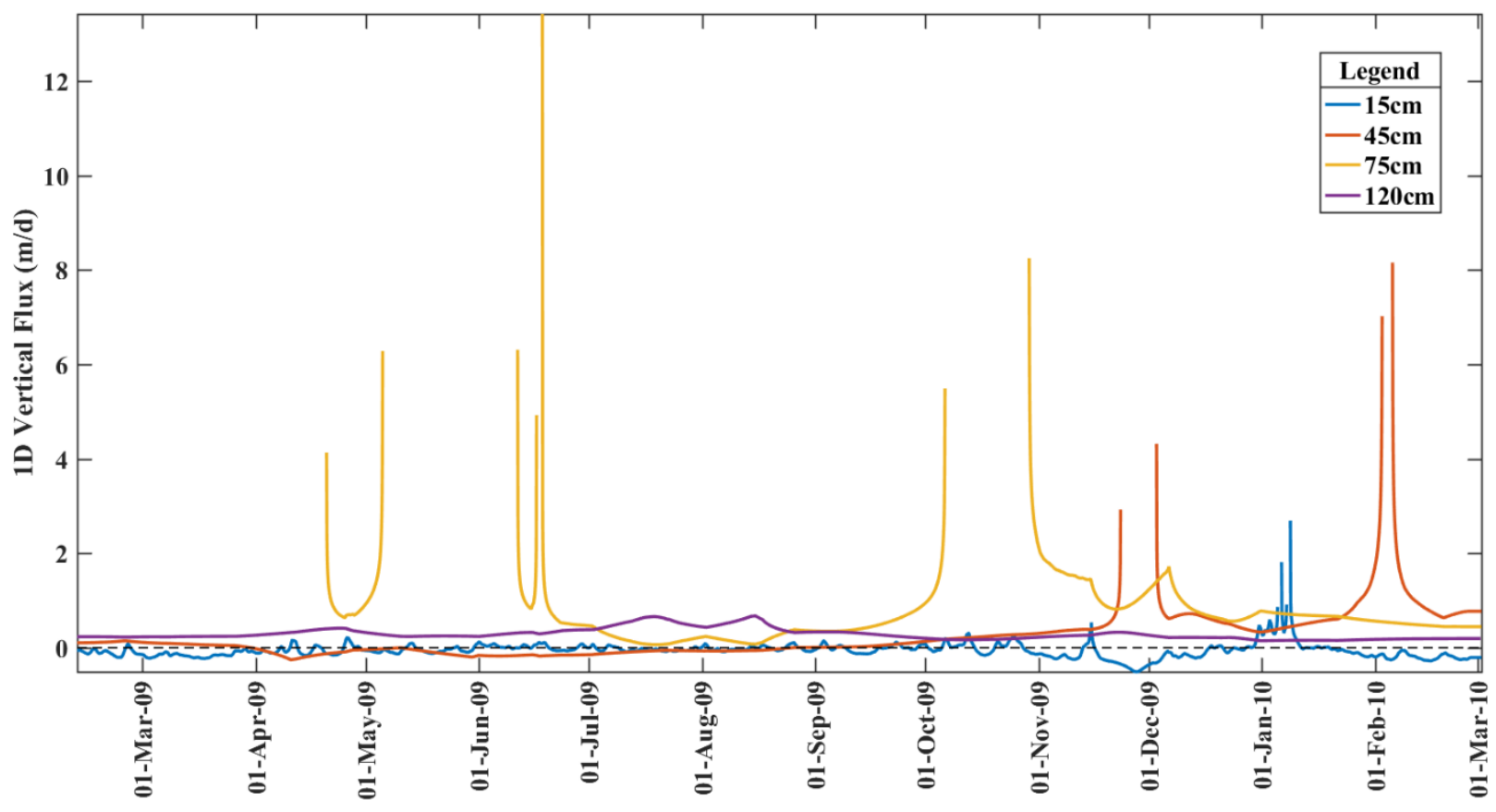

Fig. A-21 1-D vertical flux time series for midpoint depths of 15, 45, 75, and $120 \mathrm{~cm}$ for well 6. Vertical 1-D Fluxes are calculated at the midpoint between temperature sensors. 